\title{
Fates of Visual Cortical Neurons in the Ferret After Isochronic and Heterochronic Transplantation
}

\author{
Susan K. McConnell \\ Vision Center Laboratory, The Salk Insititue for Biological Studies, La Jolla, California 92037, and Department of \\ Neurobiology, Harvard Medical School, Boston, Massachusetts 02115
}

In the mammalian cerebral cortex, neurons in a given layer are generated at about the same time in development. These cells also tend to share similar sets of morphological and physiological properties and have projection patterns characteristic of that layer. This correspondence between the birthday and eventual fate of a cortical neuron suggests the possibility that the commitment of a cell to a particular laminar position and set of connections may occur very early on in cortical development. The experiments described here constitute an attempt to manipulate the fates of newly generated cortical neurons upon transplantation.

The first set of experiments addressed the normal development of neurons in the primary visual cortex (area 17) of the ferret. Injections of ${ }^{3} \mathrm{H}$-thymidine into newborn ferrets showed that neurons generated after birth are destined to sit in layer $2 / 3$ of the cortex, whereas neurons born on embryonic day (E) 32 populate primarily layers 5 and 6 . Many layer $2 / 3$ neurons in adult ferrets could be retrogradely labeled with HRP from visual cortical areas 18 and 19 , while about half of the neurons in layer 6 were found to project to the lateral geniculate nucleus (LGN).

In the second set of experiments, presumptive layer $2 / 3$ cells were labeled in vivo by injecting ferrets with ${ }^{3} \mathrm{H}$-thymidine on P1 and P2. Before the cells had a chance to migrate, they were removed from the donor brain, incubated in a fluorescent dye (DAPI or fast blue), and dissociated into a single-cell suspension. The labeled cells were then transplanted into the proliferative zone of a littermate host ferret ("isochronic" transplants). Over the next few weeks, many of these dye-labeled cells underwent changes in their position and morphology that were consistent with a radially directed migration and subsequent differentiation into cortical neurons. The final positions of isochronically transplanted neurons in the host brain were mapped out by using the ${ }^{3} \mathrm{H}$-thymidine marker after long survival periods. About $\mathbf{9 7} \%$ of radioactively labeled cells had migrated out into the

\footnotetext{
Received Apr. 13, 1987; revised Aug. 24, 1987; accepted Aug. 26, 1987.

I would like to thank Dr. Simon LeVay for his advice, encouragement, and support throughout these studies. I am grateful to Drs. C. L. Cepko, D. H. Hubel, J. E. Huettner, S. LeVay, R. D. Lund, and D. D. Potter for discussions of this work and comments on the manuscript, N. Goodknight for secretarial assistance, K. Suter for excellent animal care, and Drs. L. Eng and D. Dahl for generously donating antisera to GFA. This work was supported by NSF Grant BNS-8510425, awarded to Dr. S. LeVay.

Correspondence should be addressed to the author at her present address: Department of Neurobiology, Stanford University School of Medicine, Sherman Fairchild Science Building, Stanford, CA 94305.

Copyright (C) 1988 Society for Neuroscience $0270-6474 / 88 / 030945-30 \$ 02.00 / 0$
}

visual cortex, where they attained a compact laminar distribution: $99 \%$ were found in layer $2 / 3$, their normal destination. The labeled cells had normal, mostly pyramidal neuronal morphologies and appeared to be well integrated with host neurons when viewed in Nissl-stained sections. Ten isochronically transplanted neurons were successfully labeled after HRP injection into 2 normal target regions, areas 18 and 19. Thus, newly generated cortical neurons are capable of survival, migration, and differentiation in a host brain, and transplantation per se does not alter their fate.

In a final set of experiments, the commitment of presumptive deep-layer neurons to their normal fate was tested by challenging them to alter that fate. In these "heterochronic" transplants, cells from the occipital proliferative zone of E31 or 32 donor ferrets were labeled with ${ }^{3} \mathrm{H}$-thymidine and then transplanted into the proliferative zone of a newborn host ferret. In contrast to the isochronic transplants, about $80 \%$ of ${ }^{3} \mathrm{H}$-thymidine-labeled cells in heterochronic transplants failed to migrate and were instead found at the site where they were injected. The remainder migrated out to the visual cortex and developed neuronal morphologies. Of the labeled cells that reached the cortex, $43 \%$ were found in layer $2 / 3$, and the remaining $57 \%$ occupied the deeper cortical layers, primarily layers 5 and 6 , their normal destination. Five transplanted neurons sitting in layer 6 were retrogradely labeled from the LGN, a normal target of layer 6 cells. These results indicate that at least a subpopulation of embryonically generated neurons appears to be committed to a deeplayer fate prior to migration.

The mammalian cerebral cortex develops from the cells of the embryonic neural tube, a proliferating pool of cells that appears homogeneous under the microscope, yet somehow gives rise to a great variety of cell types that show remarkable specificity in their function. The most striking histological feature of the adult cortex is its layers, each of which is defined by the morphology of its constituent neurons and their density of packing. Cells in a given layer are furthermore characterized by having similar sets of anatomical connections and physiological properties (Gilbert and Kelly, 1975; Gilbert, 1977, 1983). Finally, neurons in the same layer tend to share a similar developmental history, since ${ }^{3} \mathrm{H}$-thymidine "birthdating" studies have shown that they go through their terminal mitotic divisions at roughly the same times (Angevine and Sidman, 1961; Rakic, 1974; Luskin and Shatz, 1985a). This correlation between a cortical neuron's birthday, its final laminar position, and its functional properties invites speculation that the young cortical neuron may be com- 
mitted to its adult fate very early on in development, perhaps before it has left the proliferative zone.

Two lines of evidence have lent at least partial support to this view. First, in the reeler mouse mutant, visual cortical neurons are generated normally, but their final migration into the cerebral cortex is disturbed in such a way that the layers form from outside-in, rather than the normal inside-out (Caviness, 1976; Pinto Lord et al., 1982). Despite their abnormal laminar positions, though, reeler neurons appear to develop normal physiological properties and connections (Caviness, 1976; Dräger, 1981; Lemmon and Pearlman, 1981). These findings suggest that normal migration is not crucial to the determination of cell type. Similar conclusions have been reached in a second line of experiments, in which the migration of cortical neurons was prevented altogether, yet some cells still formed apparently normal connections (Jensen and Killackey, 1984).

A test of whether a cortical neuron is committed to a given laminar fate is to challenge a cell to alter its normal fate, by transplanting it, for example, or by ablating its ncighbors (Stent, 1985). The present study introduces a system in which newly generated neurons are dissociated into single-cell suspensions and then reinjected into the proliferative zone of a host animal. The transplanted neurons are thereby encouraged to migrate out through the host intermediate zone and differentiate in the cortical plate, side-by-side with host neurons.

Thus, as single invaders in the host brain, the transplanted cells are subject to any environmental cues or signals that might guide or direct normal development. In these experiments, cortical neurons are transplanted into environments that differ in age from the donor, so that the currently generated host cohort of cortical neurons is destined for a different laminar fate than are the transplanted neurons. It should be noted, of course, that "fate" is a somewhat simplistic term that encompasses many properties of the adult, differentiated neuron, including its laminar position, connections, morphology, physiological properties, and transmitter choice. In this paper, however, only the first three of these properties are studied. Because in normal animals cells in a given layer tend to share common morphologies and patterns of connectivity, the term "laminar fate" is used for convenience to describe all three of these characteristics. Clearly, though, it is possible to dissociate one property from the rest, as in reeler cortex (where cells attain normal connections in spite of their abnormal positions), and it may be that different signals control these separate aspects of a cortical neuron's fate.

These experiments required an experimental animal in which all aspects of cortical development-neurogenesis, migration, and differentiation-continue after birth. Such an animal is the ferret (Mustela furo), a carnivore with a prolonged period of postnatal neurogenesis (Jackson et al., 1984). And, in addition to what has been published on the organization of the adult ferret cortex (Rockland, 1985; Zahs and Stryker, 1986), the anatomy and physiology of the visual cortex of the mink, a closely related species, have been extensively surveyed in this laboratory (McConnell and LeVay, 1984, 1986; LeVay et al., 1987).

This paper first examines the normal development of 2 sets of neurons in the ferret: postnatally generated neurons, which are destined for layer $2 / 3$ of the visual cortex, and embryonically generated cells destined for layers 5 and 6 . It then goes on to describe a transplantation system in which postnatally generated cells are removed from the proliferative zone prior to migration and transplanted back into same-age hosts. These "isochronic" transplants show that transplanted neurons are capable of a normal sequence of migration and differentiation in a host brain. In a final set of experiments, embryonically generated neurons, normally destined for the deep cortical layers, are challenged to alter their fates upon transplantation into the brains of newborn hosts ("heterochronic" transplants). This study includes and expands upon transplant results that have been published previously (McConnell, 1985a, b, 1986).

\section{Materials and Methods}

A total of 95 ferrets (Mustela furo) were used. Eighteen normal animals received injections of ${ }^{3} \mathrm{H}$-thymidine for the study of normal cortical development (14 were injected postnatally and 4 on E32). One of the postnatally injected animals also received injections of HRP into areas 18 and 19 , and HRP was injected into the LGN of one animal that had received a ${ }^{3} \mathrm{H}$-thymidine injection on E32. Both of these HRP experiments were performed after the animals had reached adulthood.

Forty-seven ferrets from 18 litters were successfully transplanted with labeled cells from littermate donors. Of these isochronic transplant animals, 8 also received injections of HRP or WGA-conjugated HRP into areas 18 and 19 several months after transplantation. An additional 5 normal adult ferrets also received HRP or WGA injections into areas 18 and 19. Finally, 4 ferrets received isochronic transplants of killed proliferative zone cells as a control.

Twenty ferrets from 6 litters received successful heterochronic transplants of cells from donor animals aged E31 ( 5 recipients) or E32 (15 recipients). Of the successfully implanted host animals allowed to survive to adulthood, 4 also received HRP injections in the LGN, and in 2, HRP was injected into areas 18 and 19. HRP injections were also placed in the LGN of one normal ferret.

Gestation lasts for $41 \mathrm{~d}$ in the ferret; here the day of birth (E41) is considered to be $\mathrm{PO}$, in concordance with the convention used by Linden et al. (1981).

\section{${ }^{3} H$-thymidine injections}

For studies of the normal development of postnatally generated neurons, ferret kits received either a single injection of ${ }^{3} \mathrm{H}$-thymidine $(50-80 \mathrm{Ci}$ / mmol; NET 027Z, New England Nuclear) in sterile aqueous solution ( $10 \mu \mathrm{Ci} / \mathrm{gm}$ body weight, i.p.) on P1 (10 animals), P4 (2 animals), or 3 injections on each of days P1 and 2 (2 animals). All of these animals were allowed to grow to maturity, except for a series of animals that were injected on P1 and then perfused on either P2, P3, P4, P6, P10, or P23 (1 animal each) in order to study the rate of migration of postnatally generated neurons.

In order to study the normal development of neurons generated on E32, ferret fetuses received a single injection of ${ }^{3} \mathrm{H}$-thymidine in sterile aqueous solution $(500 \mu \mathrm{Ci} / 0.5 \mathrm{ml})$ in utero. The procedure for making these injections was based on that of Luskin and Shatz (1985b). Briefly, the pregnant ferret was anesthetized with a mixture of ketamine hydrochloride $(50 \mathrm{mg} / \mathrm{kg})$ and xylazine $(3 \mathrm{mg} / \mathrm{kg}$, i.m.). A midline abdominal incision was made to expose the uterine horns, and ${ }^{3} \mathrm{H}$-thymidine was injected into each conceptus through a 27 -gauge needle inserted into the amniotic cavity. The abdominal skin and musculature were sutured closed and the mother was revived. Ferret kits were born normally after completion of their 41 d gestation (P0). One was perfused on P1 and the rest survived to maturity.

Ferret kits used as donor animals for isochronic transplants received multiple injections of ${ }^{3} \mathrm{H}$-thymidine to label the neurons to be transplanted: most donors were given 6 successive injections, spaced 6-12 hr apart on P1 and P2. Fetuses used as donors for heterochronic transplants also received multiple injections of ${ }^{3} \mathrm{H}$-thymidine in vivo. The uterine horns of the mother ferret were exposed as above, and the mother received additional doses of the ketamine/xylazine mixture as required to maintain a state of deep anesthesia. The donor fetuses each received 4 injections of ${ }^{3} \mathrm{H}$-thymidine $(250 \mu \mathrm{Ci} / 0.25 \mathrm{ml}$ each $)$ spaced at $1 \mathrm{hr}$ intervals. An hour after the final injection, the fetuses were removed from the uterus by cesarian section, and the mother ferret was killed with an overdose of barbiturate. 

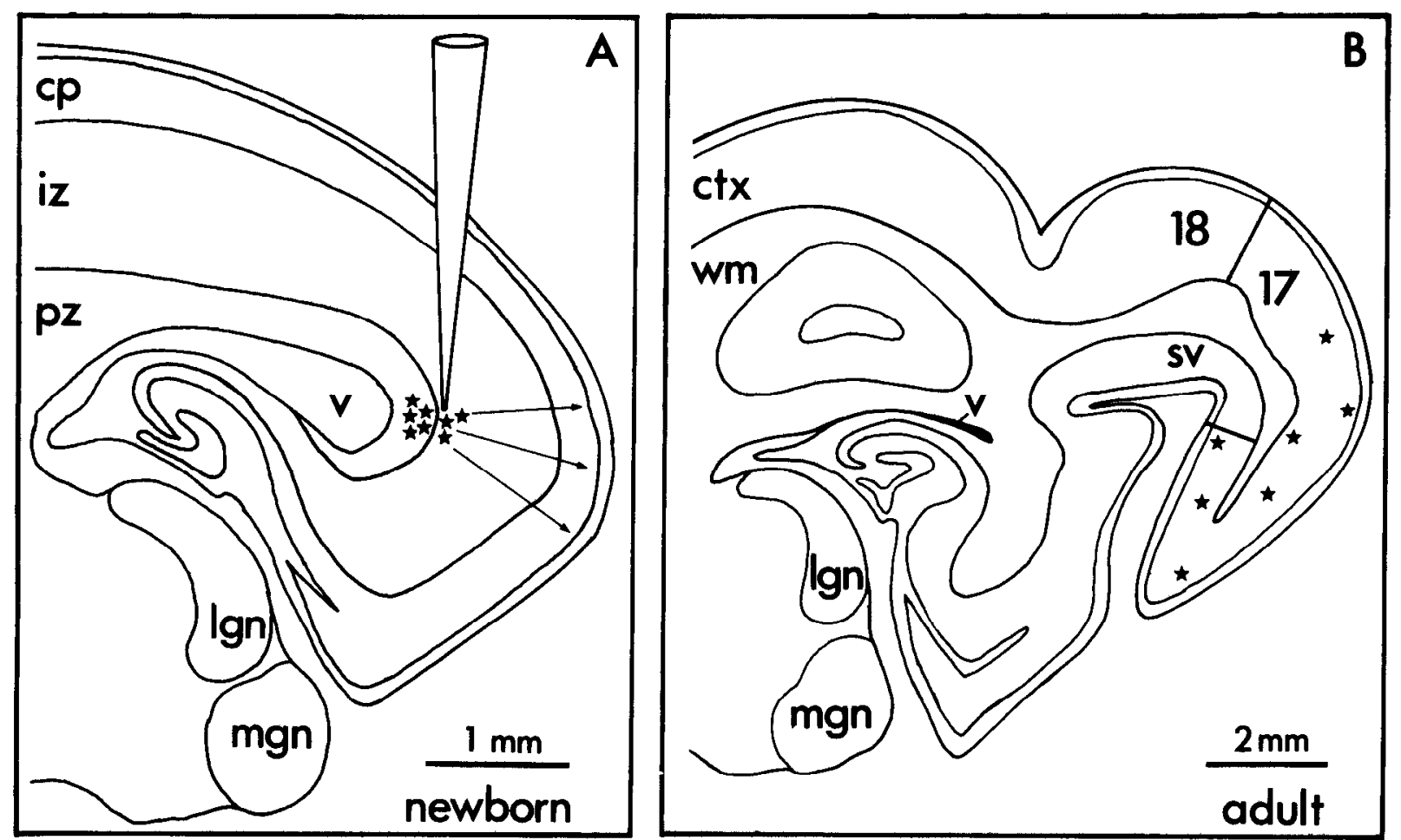

Figure 1. Methods for transplantation. A, Reconstruction of the brain of a newborn ferret, seen in parasagittal view. A pipette loaded with labeled dissociated cells (stars) is lowered into the host brain. Cells are injected by pressure into the proliferative zone $(p z)$ and the base of the intermediate zone ( $i z$ ). Transplanted cells migrate out radially (arrows) into the cortical plate ( $c p$ ), into presumptive area 17. B, Transplanted cells (stars) can be recognized at various times after transplantation by virtue of their ${ }^{3} \mathrm{H}$-thymidine or dye labels. This reconstruction of an adult brain shows the borders of area 17 with area 18 on the brain's dorsal surface and with the splenial visual area (SV) in the depth of the splenial sulcus. Abbreviations: lgn, lateral geniculate nucleus; $m g n$, medial geniculate nucleus; $c t x$, cortex; $w m$, white matter; $v$, lateral ventricle. Posterior is to the right.

\section{Methods for transplantation}

Isochronic transplants. Four to eighteen hours after the final injection of ${ }^{3} \mathrm{H}$-thymidine, donor ferrets were decapitated and the occipital poles of both cerebral hemispheres were quickly dissected out and placed in Hanks' Balanced Salt Solution (HBSS), buffered to $\mathrm{pH} 7.4$ with HEPES. The proliferative zone of cells lining the lateral ventricle (including the ventricular zone and subventricular zone, and probably parts of the lower intermediate zone as well) was then dissected free of the cortical plate and pial surface, which were thrown away. The remaining tissue was minced into small pieces with fine forceps, then incubated for 15 min in a solution of 4,6-diamidino-2-phenylindole (DAPI, $1 \mu \mathrm{M}$; Sigma) or fast blue $(0.002 \%$ in HBSS, K. G. Illing) with gentle agitation. The tissue was washed twice in fresh HBSS, and then dissociated mechanically by trituration with a fire-polished glass pipette in about $0.5 \mathrm{ml}$ HBSS to yield a dense solution of single and small clumps of cells. This procedure is a variant of that used by Huettner and Baughman (1986).

The density of the cell suspension was measured with a hemacytometer, and cell viability was calculated by the trypan blue exclusion method. Fluorescent cells were viewed under epifluorescence illumination, using a Nikon "UV" excitation filter. The dissociation procedures yielded cell survivals ranging from 55 to $90 \%$, with an average of $67 \%$, or $2.3 \times 10^{7}$ phase-bright cells $/ \mathrm{ml} \mathrm{HBSS}$. Of these, about $73 \%$ were labeled with DAPI or fast blue.

Some of the dissociated cells were allowed to attach to a polylysinecoated glass slide for $2 \mathrm{hr}$, and were then fixed with $4 \%$ paraformaldehyde in $0.1 \mathrm{M}$ phosphate buffer and processed for autoradiography (see below) in order to calculate the percentage of cells that contained both the dye and ${ }^{3} \mathrm{H}$-thymidine labels. About $30 \%$ of dye-labeled cells were also radioactively labeled.

Host ferret kits of the same age as the donor were anesthetized with ether, and their heads were stabilized with molding clay. Small holes were made in the skull and dura overlying the occipital cortex, about
1-2 mm anterior to the posterior pole of the cerebral hemisphere (which was estimated using the position of the transverse sinus, still visible through the skull, as a marker). The cell suspension was loaded into a glass micropipette (tip diameter, 20-30 $\mu \mathrm{m}$ ), which was then lowered vertically into the brain of the host ferret to a depth of $1.1-1.4 \mathrm{~mm}$. A small volume of the cell suspension, typically $0.2-0.3 \mu \mathrm{l}$, was injected by pressure into or near the host proliferative zone; the pipette was then withdrawn from the brain and the skin overlying the hole was sutured closed. On the basis of the measurements of cell density in the suspensions, it was calculated that roughly $2000-5000$ cells were injected into each host brain. The actual number may have been even less, however, because of the filtering effect of the pipette tip and because some cells adhered to the pipette glass. Another problem was that, if injections were made slightly too far anterior, cells could be lost into the ventricle. In one brain examined shortly after injection, fluorescent cells were counted in sections through the injection site: about 1200 cells were present; of these, roughly 400 would theoretically have been labeled with ${ }^{3} \mathrm{H}$-thymidine as well.

Figure 1 depicts this transplantation procedure schematically. By inserting the pipette vertically into the brain, the pipette lies at an angle roughly perpendicular to the radial glial fibers that extend from the ventricle to presumptive area 17 . Thus the transplanted neurons (stars in Fig. $1 A$ ) are afforded the opportunity to migrate out into regions of the cortical plate that are undamaged by the injection pipette (Fig. $1 A$, arrows). Isochronic hosts were allowed to survive for periods ranging from $2 \mathrm{hr}$ to 11 months following the transplantation. After histological processing, the transplanted neurons in the host brain (stars in Fig. $1 B$ ) could be identified and distinguished from host neurons by virtue of the fluorescent and/or radioactive labels.

Table 1 lists the numbers of ferrets that received isochronic transplants and their survival times. In all, 77 animals received transplants, but only 47 of these $(61 \%)$ were suitable for study. The remaining ferrets were excluded from analysis for any of the following reasons: the animal 
Table 1. Number of ferret hosts with transplants and their survival times

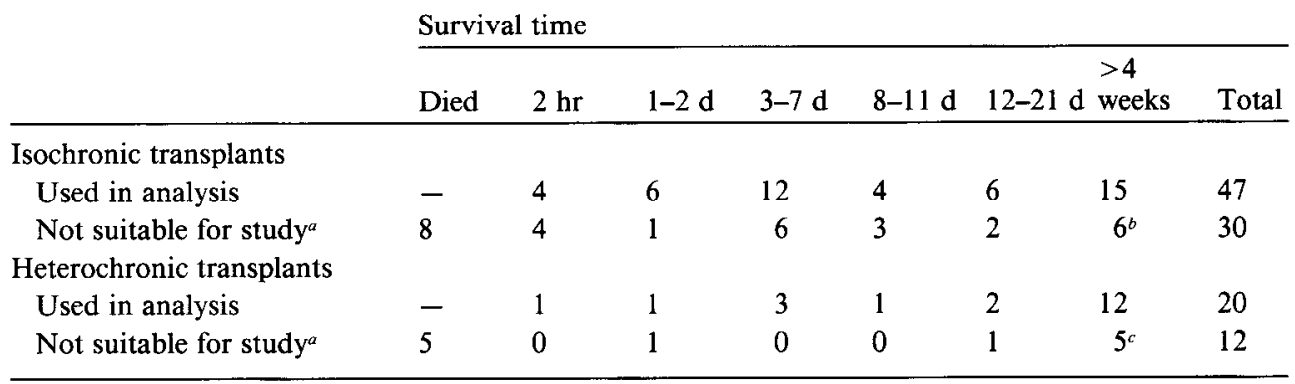

${ }^{a}$ Includes animals that died, animals in which transplants were absent or improperly positioned, and animals in which damage to the cortex caused by the injection was so severe as to obscure the results.

${ }^{b}$ In 2 of these animals, HRP was injected into areas 18 and 19, but they were excluded from the analysis because of failure of the transplant.

c All 5 of these animals also received injections of HRP into the LGN but were excluded from the analysis because of failure of the transplant.

died following transplantation, the transplant was obviously improperly positioned (e.g., too anterior-into the ventricle; too deep-into the entorhinal marginal zone), no transplanted cells were found, or the injection procedure caused so much damage to the cortex that it obscured the results of the transplant. Ferrets that survived for more than 4 weeks were grouped together and deemed mature because at these times all the cortical layers could be casily distinguished from one another, and because the neurons generated in the first few days after birth would have reached their final positions long before this time (see Results).

Control transplants. Several control transplants were performed in order to rule out the possibility that host cells might become autoradiographically labeled by incorporating ${ }^{3} \mathrm{H}$-thymidine from dead or dying transplanted cells. These transplants were performed as above, except that the labeled cells were killed by dissociation in distilled water, then resuspended in HBSS prior to transplantation. Four ferrets received transplants of these dead cells and were allowed to survive for $2 \mathrm{hr}$ or 6,12 , or $28 \mathrm{~d}$. Although diffuse ${ }^{3} \mathrm{H}$-thymidine labeling was observed over the injection site after the $2 \mathrm{hr}$ survival, no radioactively labeled cells were found in any of the other host brains.

Heterochronic transplants. The heterochronic transplants were performed in the samc manner as the isochronics, with the difference that the cortical plate could not be dissected free of the proliferative and intermediate zones prior to making the cell suspension from the fetal donor tissue. Fast blue was used as the dye label for cells in all the heterochronic transplants. In these experiments, the average suspension contained $3.2 \times 10^{7}$ phase-bright cells $/ \mathrm{ml}$, and the average viability (as assessed by trypan blue exclusion) was $65 \%$. About $59 \%$ of healthy cells were labeled with fast blue, and, of these, $35 \%$ were also labeled with ${ }^{3} \mathrm{H}$-thymidine.

Small volumes of the cell suspension $(0.2-0.3 \mu \mathrm{l})$ were transplanted into the proliferative zone of $\mathbf{P} 2$ ferret hosts, which were allowed to recover and survive for periods ranging from $2 \mathrm{hr}$ to several months following transplantation. Table 1 lists the number of ferrets that received heterochronic transplants and their survival times. Transplants wcre made into a total of 32 animals, but only 20 of these $(62 \%)$ were suitable for study. This success rate is similar to that for isochronic transplants.

\section{Tracer injections}

Several ferrets received multiple injections of HRP or WGA into areas 18 and 19 , or into the LGN, in order to retrogradely label the cells in area 17 that project to these areas. Ferrets were anesthetized with a mixture of ketamine hydrochloride $(50 \mathrm{mg} / \mathrm{kg})$ and xylazine $(3 \mathrm{mg} / \mathrm{kg}$, i.m.); supplemental doses were given as required. Atropine was used to dilate the pupils and phenylephrine to retract the nictitating membranes. Rectal temperature was monitored and maintained at $38-40^{\circ} \mathrm{C}$ (Moody et al., 1985). For injections of cortical areas, the animals were placed in a stereotaxic apparatus, and a large hole was drilled in the skull overlying areas 18 and 19 , the bulk of which lies on the dorsal surface of the cerebral hemispheres just rostral to area 17 (Rockland, 1985; see McConnell and LeVay, 1986, for comparable data in the mink). In many animals, the $17 / 18$ border was identified physiologically using a tungsten microelectrode (tip impedance 10-20 M $\Omega$ at $1 \mathrm{kHz}$ ); the electrode was then replaced with a glass micropipette containing a solution of HRP (Boehringer Mannheim; see Table 2 for exact percentages) and $3 \%$ lysolecithin (Sigma) in $0.9 \% \mathrm{NaCl}$ (Frank et al., 1980), or of $1 \%$ WGA (Sigma) in saline. Injections were made by pressure through a length of polyethylene tubing that allached the micropipette to a syringe. Typically about 20 injections of $0.05-0.1 \mu \mathrm{l}$ each were made at $1 \mathrm{~mm}$ intervals over the cortical surface, in order to maximize the extent of retrograde labeling in area 17 (see Table 2 for details). Injections in the LGN were made using similar methods. In short, after drilling a hole in the skull overlying the LGN, the nucleus was explored briefly with a tungsten microelectrode, which was then replaced with a glass micropipette containing the tracer solution. Typically, multiple injections of the tracer were made at various points in the visual-field representation in an attempt to inject as much of the structure as possible (see Table 2 for details). Following the HRP injections, animals recovered from surgery and survived for $48 \mathrm{hr}$ to allow for transport of the tracer.

\section{Perfusions and histological procedures}

Prior to perfusion, ferrets were killed with an overdose of barbiturate. All animals except those injected with HRP or WGA were perfused through the heart with normal saline, followed by Formol saline or $4 \%$ paraformaldehyde in $0.1 \mathrm{M}$ phosphate buffer. Their brains were removed and sunk in $20-30 \%$ sucrose in fixative; they were then sectioned at 20 $\mu \mathrm{m}$ on a freezing microtome in the parasagittal plane. Brains of young animals were either embedded in gelatin-albumin prior to sectioning, or were embedded in glycol methacrylate and cut at $5 \mu \mathrm{m}$ on an LKB Historange microtome. Sections were mounted and dried on gelatinsubbed slides. Some of these were examined under fluorescence microscopy for the presence of dye-labeled cells: these sections were cleared briefly in $100 \%$ ethanol $(30 \mathrm{sec})$ and xylene $(30 \mathrm{sec})$, and were coverslipped with Krystalon (Harleco, Gibbstown, NJ). Other sections were processed for autoradiography: they were defatted in xylene, dipped in $2 \%$ gelatin, and coated with Kodak NTB2 nuclear track emulsion. After 6 weeks in the dark at $4^{\circ} \mathrm{C}$, they were developed with Kodak D-19, fixed with Kodak Rapid Fix, and counterstained with cresyl violet. Sections that were used for both fluorescence and autoradiography were not defatted or counterstained.

Cells that were labeled with ${ }^{3} \mathrm{H}$-thymidine could be identified by an accumulation of silver grains overlying the cell's nucleus. A heavily labeled cell was defined as one with at least half of the maximal number of silver grains found over the most heavily labeled cells in that animal. With practice, however, heavily labeled cells were reliably distinguished from unlabeled and lightly labeled cells (which had presumably under- 
Table 2. Animals used in tracer experiments

\begin{tabular}{llllrrl}
$\begin{array}{l}\text { Animal } \\
\text { no. }\end{array}$ & Previous experiment & Injection site & Tracer used & $\begin{array}{l}\text { Concentra- } \\
\text { tion of } \\
\text { tracer }(\%)\end{array}$ & $\begin{array}{l}\text { No. of } \\
\text { injections }\end{array}$ & $\begin{array}{l}\text { Total } \\
\text { volume } \\
(\mu \text { l) }\end{array}$ \\
\hline 149 & ISO & 18 & WGA & 1 & 1 & 0.05 \\
150 & ISO & 18,19 & HRP & 30 & 25 & 0.75 \\
154 & - & 18 & WGA & 1 & 1 & 0.05 \\
165 & ISO & 18,19 & HRP & 30 & 29 & 1.04 \\
166 & ISO & 18,19 & HRP & 30 & 30 & 1.44 \\
167 & ISO & 18,19 & HRP & 30 & 30 & 1.44 \\
169 & ISO & 18,19 & HRP & 30 & 30 & 1.44 \\
176 & - & 18 & HRP & 20 & 8 & 0.86 \\
177 & - & 18,19 & WGA & 1 & 8 & 0.38 \\
186 & - & 18,19 & WGA & 1 & 7 & 0.34 \\
187 & - & 18,19 & HRP & 30 & 16 & 0.58 \\
191 & E32 ${ }^{3}$ H-Thy & LGN & HRP & 30 & 1 & 0.18 \\
196 & HET & LGN & HRP & 20 & 3 & 0.30 \\
197 & HET & LGN & HRP & 20 & 8 & 0.78 \\
198 & HET & LGN & HRP & 20 & 12 & 1.11 \\
199 & HET & LGN & HRP & 20 & 17 & 2.04 \\
225 & P1,2 ${ }^{3}$ H-Thy & 18,19 & HRP & 20 & 17 & 1.02 \\
231 & - & LGN & WGA & 1 & 1 & 0.30 \\
237 & ISO & 18,19 & HRP & 20 & 24 & 2.16 \\
238 & ISO & 18,19 & HRP & 20 & 21 & 1.89 \\
241 & HET & 18,19 & HRP & 20 & 20 & 1.80 \\
242 & HET & 18,19 & HRP & 20 & 25 & 2.25 \\
\hline 150, & & & & & \\
\hline
\end{tabular}

ISO, isochronic transplant; HET, heterochronic transplant; $\mathrm{P} 1,2{ }^{3} \mathrm{H}-\mathrm{Thy}$, animal received injections of ${ }^{3} \mathrm{H}$-thymidine on P1 and 2; E32 ${ }^{3} \mathrm{H}-$ Thy, animal received injections of ${ }^{3} \mathrm{H}$-thymidine on E32; LGN, lateral geniculate nucleus; 18,19 , visual cortical areas 18 and 19 .

gone further rounds of mitotic division and diluted out the ${ }^{3} \mathrm{H}$-thymidine) by simple inspection; labeled cells were therefore generally identified by eye rather than by counting grains.

Ferrets that received HRP or WGA injections were perfused with icecold phosphate buffer ( $\mathrm{pH} 7.4$ ), followed by $1 \%$ paraformaldehyde, $2 \%$ glutaraldehyde in buffer. The brains were removed and sunk in $30 \%$ sucrose in buffer overnight at $4^{\circ} \mathrm{C}$. Blocks of tissue were frozen-sectioned in the parasagittal plane at $20 \mu \mathrm{m}$. Sections were then reacted for HRP using either the diamidinobenzidine (DAB) method of Mesulam (1978) or the tetramethylbenzidine (TMB) method of Olucha et al. (1985), coupled with a method for stabilizing the TMB reaction product with DAB and cobalt (Rye et al., 1984). In many animals, the HRP-reacted sections were then processed for autoradiography. The best results were achieved when the reacted sections were postfixed overnight in $4 \%$ paraformaldehyde in $\mathrm{pH} 7.4$ phosphate buffer, then mounted from water onto glass slides subbed in $30 \%$ ethanol, $7 \%$ acetic acid, $1.5 \%$ gelatin, and $0.1 \%$ chrome-alum. The sections were dried, defatted in alcohols and xylene, rinsed in running distilled water for $1 \mathrm{hr}$, then processed for antoradiography as described above.

\section{Immunocytochemistry}

To examine dye-labeled cells for immunoreactivity to glial fibrillary acidic protein (GFA), relevant sections were washed 3 times in PBS, then incubated for $1 \mathrm{hr}$ in $0.5 \%$ Triton X-100 plus 3\% normal goat serum (NGS) in PBS at room temperature. Sections were then incubated overnight at $4^{\circ} \mathrm{C}$ on a rotating table in rabbit antisera to GFA (generously donated by L. Eng and D. Dahl) diluted 1:150 in 0.5\% Triton X-100, $3 \%$ NGS, and $2 \%$ RSA in PBS. After 3 washes with $0.5 \%$ Triton X-100 and 3\% NGS in PBS, the sections were placed in L-rhodamine-conjugated goat anti-rabbit immunoglobulin (Boehringer Mannheim) diluted $1: 40$ in $0.5 \%$ Triton $X-100$ and $3 \%$ NGS in PBS. The sections were finally rinsed 3 times with PBS and mounted onto subbed slides. Im- munoreactive cells and processes were visualized using rhodamine epifluorescence optics, using a Nikon " $G$ " excitation filter.

\section{Results}

Normal development of ferret visual cortex

The cerebral mantle of the ferret undergoes a tremendous expansion and development in the first 2 months after birth. Figure 2 shows 3 sections through the ferret's occipital cerebral mantle at 3 different ages, all at the same magnification. Shortly after birth (Fig. $2 A$ ), the mantle measures only about $1.1 \mathrm{~mm}$ from the ventricular to pial surfaces. The cortical plate is visible as a cell-dense layer underlying the marginal zone, or future layer 1 , at the pial surface. The subplate lies subjacent to the cortical plate, and under it are the migrating cells and axons of the intermediate zone (future white matter). At this age the ventricular and subventricular zones are still quite substantial in thickness. By $10 \mathrm{~d}$ after birth, the cortical plate has undergone a marked expansion in size (Fig. $2 B$ ). Not only is the plate thicker, but layers 5 and 6 can now be distinguished from the more compact upper layers. All the cortical laminae are recognizable in animals after the age of about 3 weeks (Fig. 2C), even though the cells in each layer have probably not completed their morphological differentiation. In the adult ferret, the visual cortcx attains a thickness of about $1.1 \mathrm{~mm}$-roughly the size of the entire cerebral mantle of the newborn.

The transplantation experiments described later in this paper required that the transplanted cells be introduced into an en- 

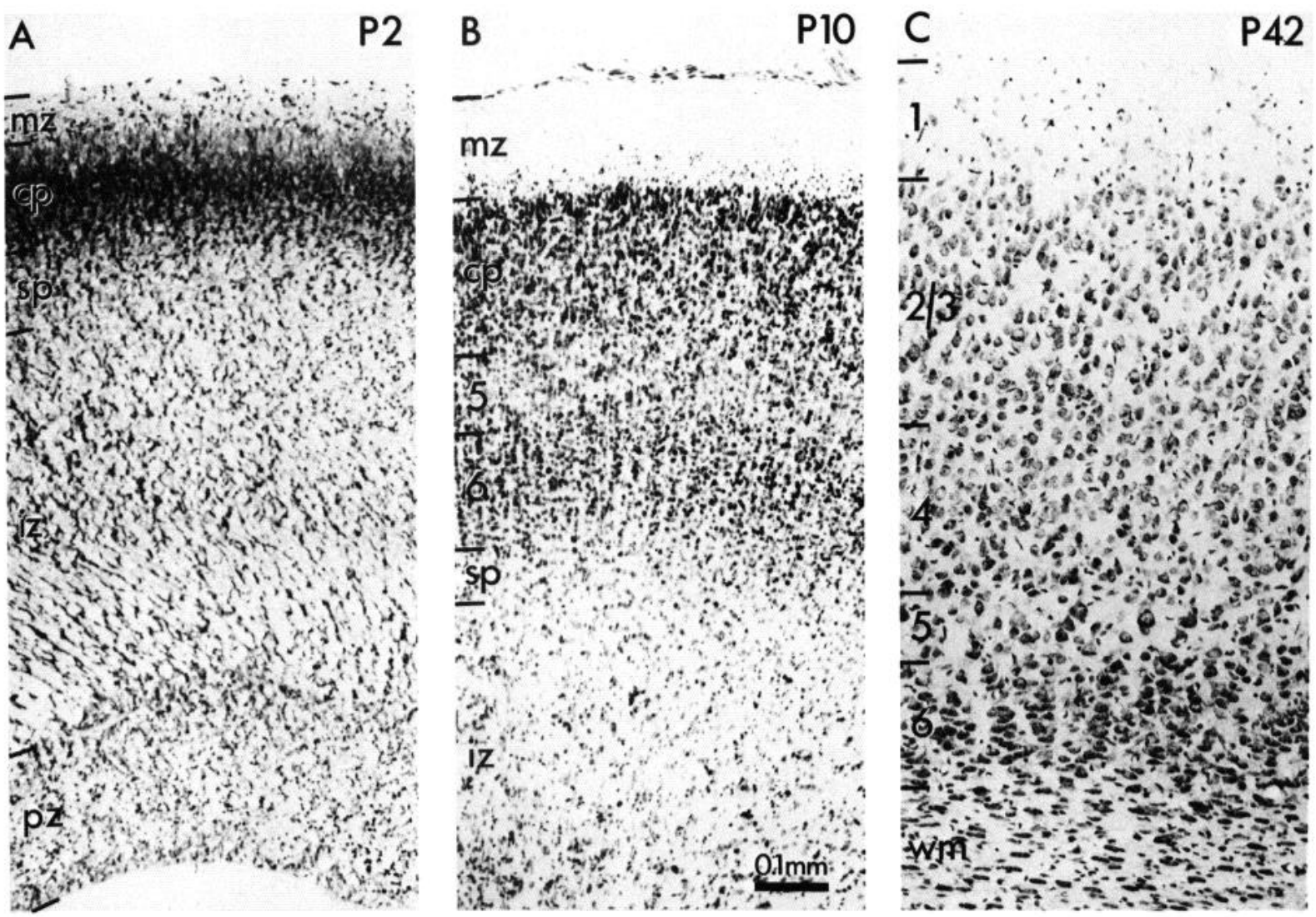

Figure 2. The ferret's occipital cerebral mantle at 3 different ages, all at the same magnification. $A$, On $\mathrm{P} 2$ the entire cerebral mantle is only about $1.1 \mathrm{~mm}$ in thickness. The cortical plate $(\mathrm{cp})$ is a relatively undifferentiated cell-dense layer underlying the marginal zone $(\mathrm{mz})$, or future layer 1 . The proliferative zone $(p z)$ is still quite thick at this age. Young neurons migrate through the intermediate zone $(i z)$ and subplate $(s p)$ to the top of the cortical plate. $B$, By P10, layers 5 and 6 are recognizable. The cortical plate is much thicker. $C$, By P42, all the layers can be recognized, and the cortex is now nearly as thick as the entire cerebral mantle was on P2. $w m$, White matter.

vironment in which neurogenesis, migration, and differentiation are ongoing in the cerebral mantle. That cortical neurogenesis might continue postnatally in the ferret was suggested by the immature state of the ferret's cerebral hemispheres at birth, the newborn's altricial appearance, and the known immaturity of the postnatal retinogeniculate system in the ferret (Linden et al., 1981). To test this, several newborn ferrets were given injections of ${ }^{3} \mathrm{H}$-thymidine in order to mark the birthday and study the development of any neurons generated on a given postnatal day. Another group of ferrets received ${ }^{3} \mathrm{H}$-thymidine injections on E32 in order to track the normal development of the presumptive deep-layer neurons that form the focus of the heterochronic transplants. The development and ultimate fates of these 2 select groups of normal cortical neurons tagged with radioactive thymidine are presented below. A complete ${ }^{3} \mathrm{H}$-thymidine birthdating study of visual cortical neurons in the ferret has been undertaken by Jackson et al. (1984); they have shown that, indeed, cortical neurons continue to be generated for roughly 2 weeks postnatally in the ferret.

Laminar position of postnatally generated neurons. Figure 3 is a dark-field autoradiograph of a section through the brain of a ferret that received an injection of ${ }^{3} \mathrm{H}$-thymidine on $\mathrm{P} 1$ and was then allowed to grow up to adulthood. In this parasagittal view, it can be seen that area 17 occupies the posterior lip of the cerebral hemisphere, running anteroventrally down the tentorial surface, then curling up into the splenial sulcus. Area 17 is bordered by area 18 on the brain's dorsal surface, and by the splenial visual area (SV) at its peripheral margin (for a description of the layout of the visual field in these areas in the mink, see McConnell and LeVay, 1986). The small white dots visible in Figure 3 are cells labeled with ${ }^{3} \mathrm{H}$-thymidine. In general, there was a rostral-to-caudal gradient of labeling, as in other mammals (Rakic, 1974; Luskin and Shatz, 1985a), with only a few, very superficial, cells labeled at the frontal pole of cortex.

The distribution of ${ }^{3} \mathrm{H}$-thymidine-labeled cells in area 17 of the ferret's cortex is shown at higher power in Figure 4. The most heavily labeled cells were found in the bottom half of layer $2 / 3$, with more lightly labeled cells sitting more superficially. When ${ }^{3} \mathrm{H}$-thymidine was injected on $\mathrm{P} 4$, labeled cells in the adult were found to be positioned slightly more superficially than with the Pl injection, as would be expected from the known, inside-out gradient of corticogenesis in mammals (Angevine and Sidman, 1961; Rakic, 1974; Jackson et al., 1984; Luskin and Shatz, 1985a). In order to quantify the laminar distribution of cortical neurons generated on P1, heavily labeled cells were counted in 2 animals (in both central and peripheral regions of area 17), and their laminar locations are plotted in Figure 5. The vast majority of neurons generated on P1 came to occupy layer $2 / 3$, with a few cells scattered in other layers (primarily layer 4). Although only laminar position, and not depth within the layer, was plotted, again labeled cells in layer $2 / 3$ tended to be found at the base of the layer. This differs slightly from the results of Jackson et al. (1984), who found more cells labeled in upper layer 4 than were found here. In addition to the thy- 


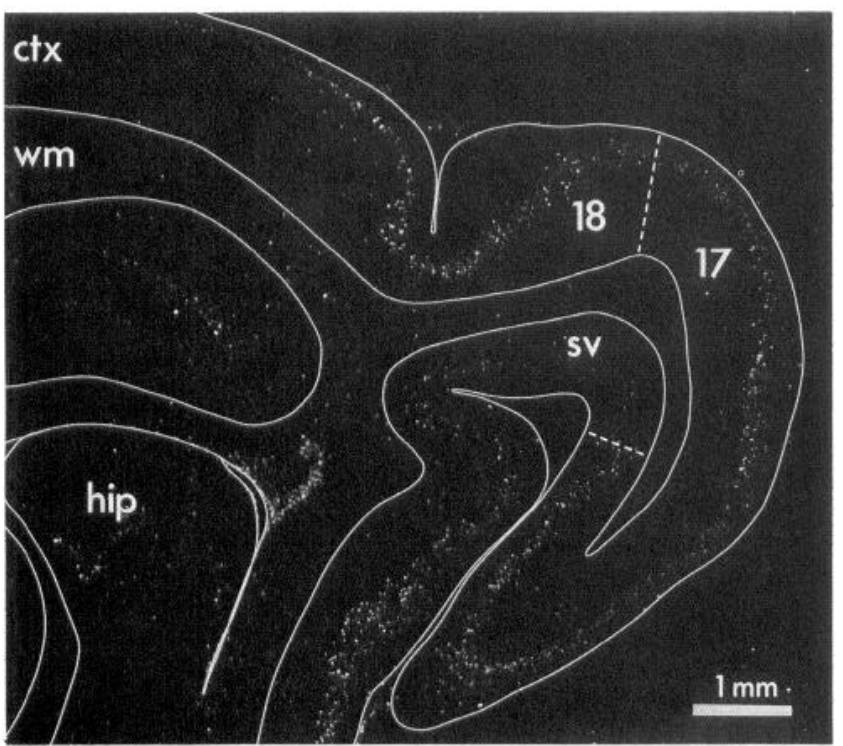

Figure 3. Dark-field autoradiograph from an adult ferret that was injected with ${ }^{3} \mathrm{H}$-thymidine on $\mathrm{P} 1$. The band of white dots is composed of ${ }^{3} \mathrm{H}$-thymidine-labeled cells. Abbreviations: $c t x$, cortex; $w m$, white matter; hip, hippocampus; $s v$, splenial visual area. Posterior is to the right.

midine-labeled cells in the cortex, some cells in the remnant of the embryonic proliferative zone near the lateral ventricle were also labeled in each animal studied.

In one series of experiments, animals were injected with ${ }^{3} \mathrm{H}$ thymidine on $\mathrm{Pl}$ and killed at various intervals thereafter, in order to study the rate of migration of presumptive layer $2 / 3$ neurons out to the cortical plate. Reconstructions of representative sections from these animals are shown in Figure 6. One day after injection, the majority of ${ }^{3} \mathrm{H}$-thymidine-labeled cells were still in the proliferative zone, although some had apparently already begun their migration and were found in the lower half of the intermediate zone. By P6, a few labeled cells had reached the cortical plate, and by $9 \mathrm{~d}$ after the injection (P10), many were found at the top of the cortical plate, in the compact zone of cells bordering the marginal zone. By P23, the thymidine-labeled cells appeared to have achieved their adult distribution: most were in the lower portion of layer $2 / 3$ (which was still characterized by a compact zone of cells at its top, probably consisting of young neurons newly arrived in the cortex); a smaller population of labeled cells was also found in the remnant of the proliferative zone near the ventricular surface. Thus, newly generated neurons destined for layer $2 / 3$ took about a week or so to travel from the proliferative zone to the cortical plate, migrating at a rate of approximately $10-15 \mu \mathrm{m} / \mathrm{hr}$.

Axonal connections from area 17 to areas 18 and 19. The axonal projections of neurons sitting in layer $2 / 3$ of the visual cortex were studied by retrograde labeling with HRP in both normal adult ferrets and an adult ferret that had received injections of ${ }^{3} \mathrm{H}$-thymidine as a neonate (see Table 2 for details). The purpose of these experiments was not so much to thoroughly explore all the projections from the upper layers of area 17 as it was to document a pair of the major projections. Areas 18 and 19 receive a strong input from the upper layers of area 17 in other carnivores (Gilbert and Kelly, 1975; Symonds and Rosenquist, 1984; McConnell and LeVay, 1986); in order to assess later whether transplanted neurons formed normal axonal con-

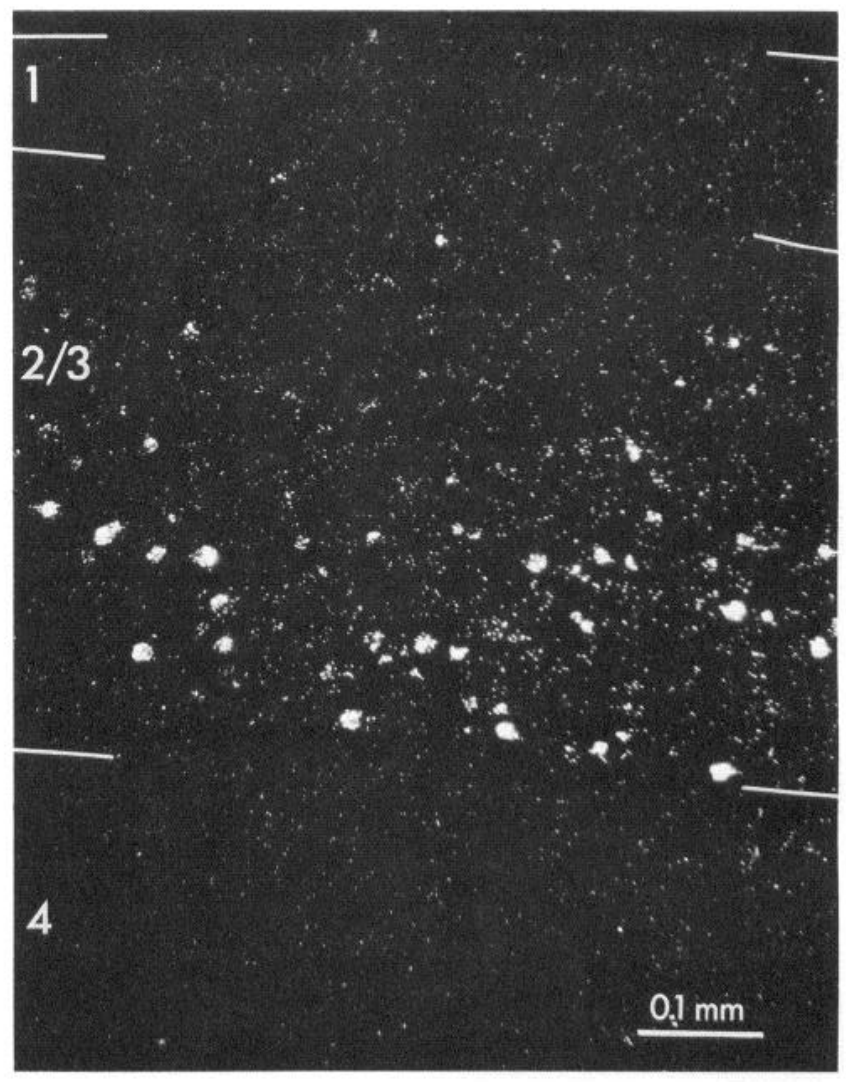

Figure 4. High-power view of ${ }^{3} \mathrm{H}$-thymidine-labeled cells in area 17, dark-field autoradiograph. Heavily labeled cells are found at the base of layer 2/3. (From McConnell, 1985; used with permission from American Association for the Advancement of Science.)

nections (see below), attention was here focused on the set of projections that was deemed most characteristic of the superficial layers.

In most ferrets, a series of injections of HRP was made into the dorsal cortex at $1 \mathrm{~mm}$ intervals, covering much of areas 18

\section{$\mathrm{P1}[3 \mathrm{H}]$ thy injection}

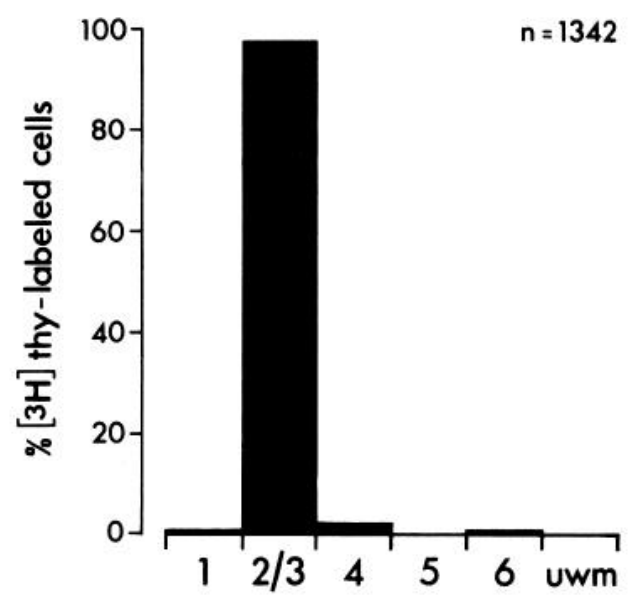

Figure 5. Distribution of heavily labeled neurons in area 17 of the adult ferret after ${ }^{3} \mathrm{H}$-thymidine injection on P1. Nearly all labeled cells were in layer $2 / 3$. uwm, White matter directly underlying layer 6 . 


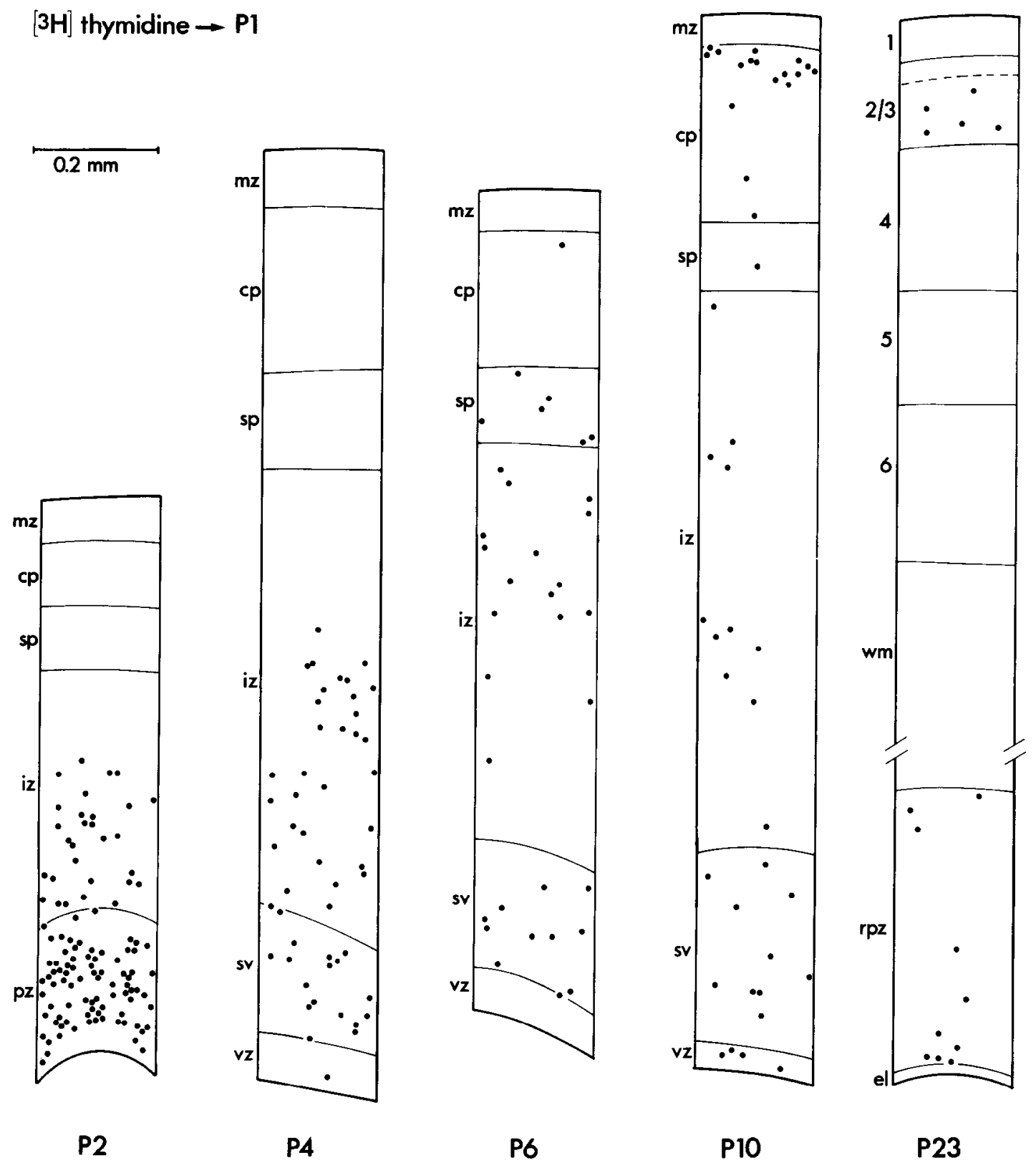

Figure 6. Series of reconstructions of the positions of radioactively labeled cells (dots) at different times after an injection of ${ }^{3} \mathrm{H}$-thymidine on $\mathrm{P} 1$. On P2 and P4, labeled cells are found primarily in the lower half of the intermediate zone $(i z)$ and in the proliferative zone ( $p z)$, which includes both the ventricular zone $(v z)$ and subventricular zone $(s z)$. By P6, labeled cells are found in the subplate (sp) and cortical plate ( $c p$ ). At P10, many labeled cells are clustered at the top of the cortical plate, just below the marginal zone $(m z)$. By P23, labeled cells are in their final positions in layer 2/3; some remain in the remnant of the proliferative zone $(r p z)$ that overlies the ependymal layer (el). A compact zone of poorly differentiated cells at the top of the cortex (dashed line) contains the most recently arrived neurons.

and 19. Figure $7 A$ shows 2 injection sites in area 18 (perhaps extending into area 19) out of a total of 17 such injections (ferret no. 225). (It is possible that cortical areas anterior to area 19 were injected as well in some animals; nevertheless, in the cat, the great majority of all cortically projecting cells in area 17 are found in layer 2/3; Symonds and Rosenquist, 1984.) The distribution of HRP-labeled neurons in a small region of area 17 (box in Fig. $7 A$ ) is reconstructed in Figure $7 D$ (outlined cells). Neurons in area 17 that were retrogradely labeled with HRP from areas 18 and 19 were found predominantly in layer 2/3; however, as in both the mink (McConnell and LeVay, 1986) and cat (Meyer and Albus, 1981), a second tier of labeled neu- rons (more sparse than the first) was also observed in layers 5 and 6 , mostly along the $5 / 6$ border. HRP-labeled neurons were typically distributed in patches along the tentorial surface of area 17 , but tended not to be found in the representation of the far periphery of the visual field, which is tucked into the splenial sulcus. Nor were neurons in the peripheral visual-field representation of the LGN labeled after these extensive injections. This is probably due to there being only a limited representation of the periphery in the ferret's prestriate cortical areas; in the mink, the representation of the horizontal meridian in area 18 extends to only about $40^{\circ}$ of azimuth, even though the mink's field of view extends out to $130^{\circ}$ azimuth (McConnell and LeVay, 


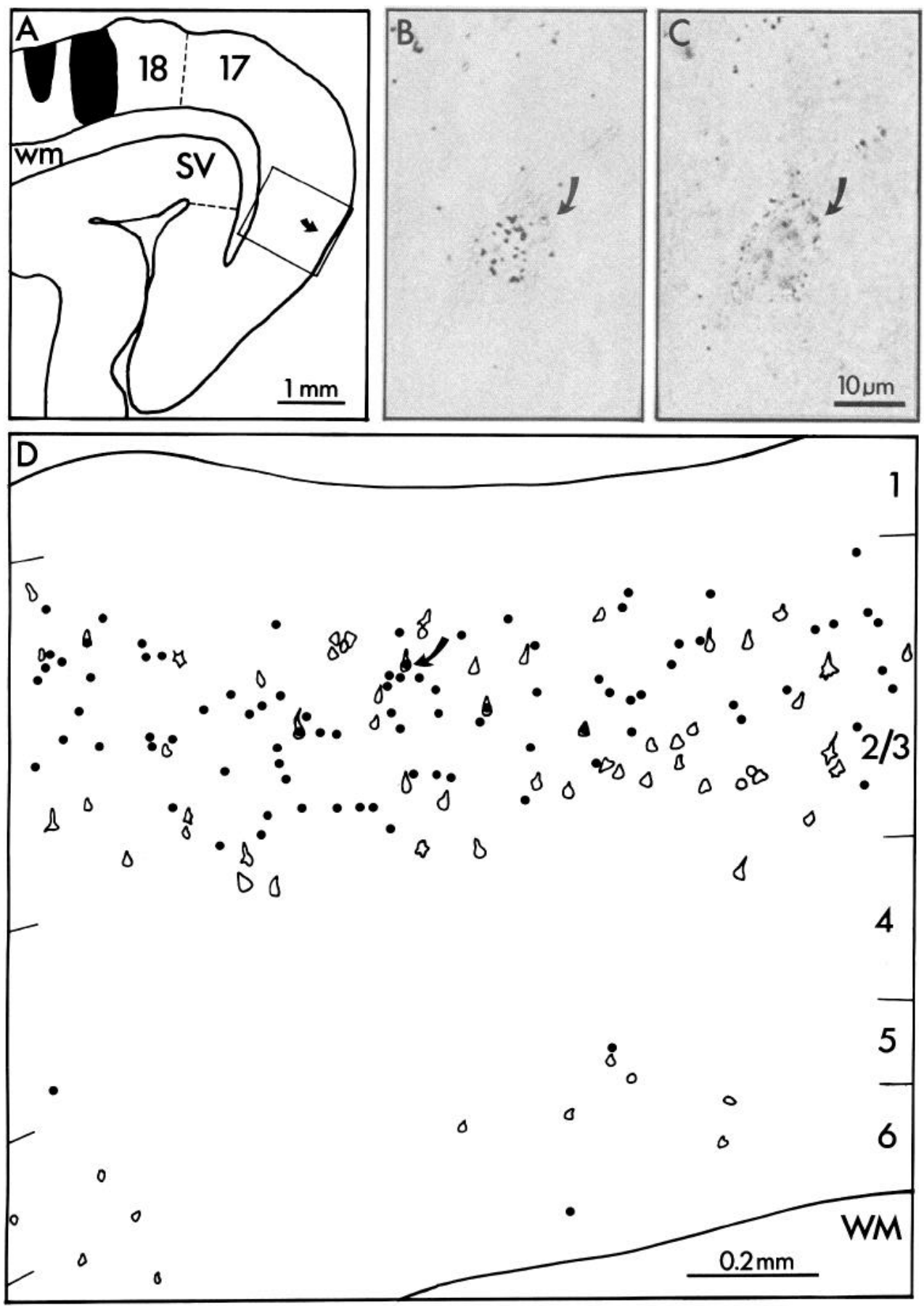

Figure 7. Results of an experiment in which an adult ferret that had been injected with ${ }^{3} \mathrm{H}$-thymidine on $\mathrm{P} 1,2$ received multiple injections of HRP into areas 18 and 19. $A$, Reconstruction of a section showing 2 of the 17 HRP injection sites in areas 18 and 19 , on the dorsal surface of the brain. Posterior is to the right. Retrogradely labeled cells were found in area 17 and in the splenial visual area $(S V)$. HRP- and ${ }^{3} \mathrm{H}$-thymidine-labeled cells in a small region of area 17 (box) are reconstructed in $D$, and the arrow in $A$ points to the same double-labeled cell shown in $B$ and $C$. $B$, A ${ }^{3} \mathrm{H}$-thymidine-labeled neuron in area 17 (arrow in $A$ ), plane of focus on the silver grains overlying the cell's nucleus. $C$, Same cell as in $B$, with the plane of focus now on the HRP reaction product in the cell body. This cell was generated on P1 or P2 and developed an axonal projection to area 18 or 19 . $D$, Reconstruction of the positions of neurons retrogradely labeled with HRP (outlined) or labeled with ${ }^{3} \mathrm{H}$-thymidine (dots) from the area boxed in $A$. A few cells (e.g., arrow) contain both labels. Retrogradely labeled neurons occupied 2 bands: most were in layer $2 / 3$, while a few were found in the infragranular layers. Although the spatial overlap of the 2 populations of labeled neurons was good, few cells were double-labeled.
1986). Retrogradely labeled neurons were also seen in area SV of the ferret after injection of areas 18 and 19 (not shown), as has also been observed in the mink (McConnell and LeVay, 1986). As in area 17, HRP-labeled neurons were concentrated in layer $2 / 3$, although a few were found in the infragranular layers as well.

In addition to the distribution of HRP-labeled neurons in area 17 , Figure $7 D$ shows the positions of many autoradiographically labeled cells (dots); this animal had previously received injections of ${ }^{3} \mathrm{H}$-thymidine on $\mathrm{P} 1$ and 2 . A subpopulation of neurons in layer $2 / 3$ was both retrogradely labeled with HRP and heavily labeled with ${ }^{3} \mathrm{H}$-thymidine; one such cell (arrow in Fig. $7 D$ ) is shown in Figure $7, B, C$. Note also in Figure $7 D$ that, although the 2 populations of labeled neurons in layer $2 / 3$ almost entirely overlapped in their spatial extent, the number of doublelabeled cells was small. This was because each marker labeled less than $10 \%$ of the total neuronal population in this region of layer $2 / 3$. Assuming that the probability of finding a doublelabeled cell is the product of the individual probabilities of single-labeling, fewer than $1 / 100$ neurons would be expected to show double-labeling, a fraction comparable to that actually observed.

Development of normal E32 neurons. One goal of this part of the study of normal cortical development was to select a time at which presumptive deep-layer neurons were being generated, so that these cells could be transplanted in later experiments. 


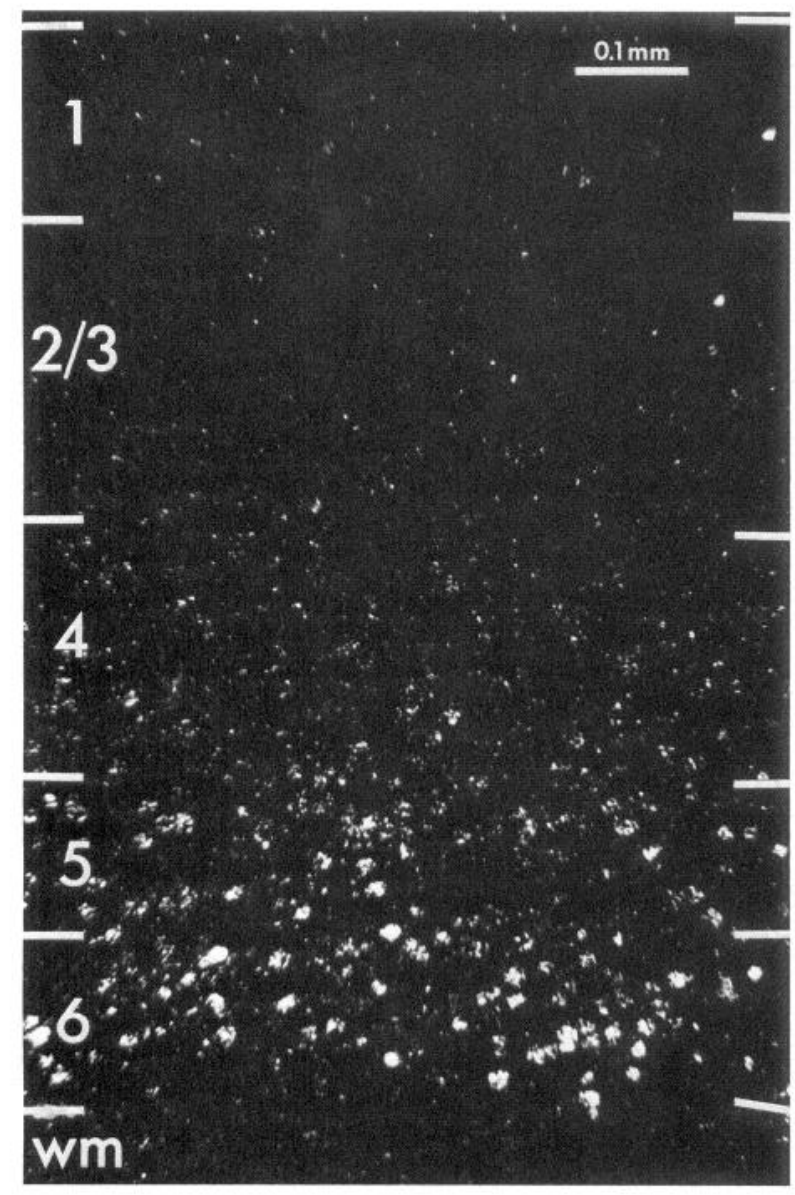

Figure 8. Dark-field autoradiograph in area 17 of an adult ferret that received an injection of ${ }^{3} \mathrm{H}$-thymidine on E32. Heavily labeled cells were found predominantly in layers 5 and 6 , and lightly labeled cells were more superficially located. $w m$, White matter.

On the basis of a complete ${ }^{3} \mathrm{H}$-thymidine birthdating study of the ferret's visual cortex (Jackson et al., 1984), E32 was selected as such a time. In order to confirm Jackson et al.'s (1984) results, ${ }^{3} \mathrm{H}$-thymidine injections were made into several E32 fetuses, which were subsequently delivered normally and allowed to grow to adulthood. A dark-field autoradiograph from area 17 of one such ferret is shown in Figure 8: indeed, the majority of neurons heavily labeled with ${ }^{3} \mathrm{H}$-thymidine were found in layers 5 and 6 . In order to quantify the laminar distribution of labeled neurons after an E32 injection, the laminar positions of heavily labeled cells from both the central and peripheral visual-field representations in area 17 were tallied up in one animal and are presented in histogram form in Figure 9. About $85 \%$ of labeled cells were found in layers 5 and 6 . Overall, there was a fair amount of scatter in the positions of heavily labeled cells, certainly more than was observed after an injection of ${ }^{3} \mathrm{H}$-thymidine on Pl (Fig. 5). Not apparent from this histogram is the finding that labeled cells in layer 6 tended to be found in the upper two-thirds of the layer, but this can be seen from the distribution of ${ }^{3} \mathrm{H}$-thymidine-labeled cells (dots) reconstructed in Figure 11.

This study did not examine the normal rate of migration of cells generated on E32 out to the cortical plate. However, it was of interest to know whether these neurons had reached their final destination in the deep layers by the time of birth, $9 \mathrm{~d}$

\section{E32 $[3 \mathrm{H}]$ thy injection}

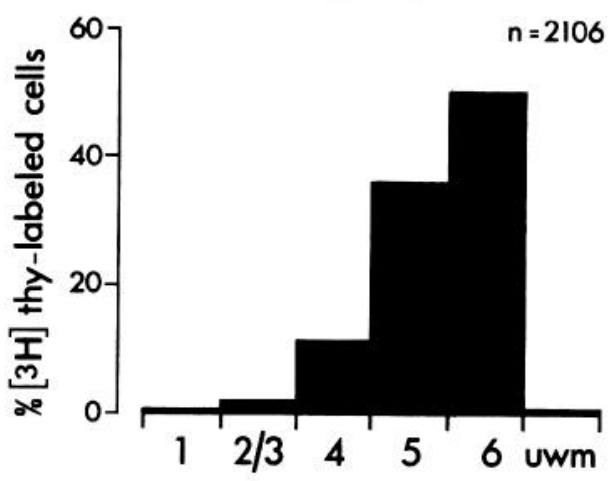

Figure 9. Distribution of heavily labeled neurons in area 17 of an adult ferret after an injection of ${ }^{3} \mathrm{H}$-thymidine on E32. Overall, about $80 \%$ of labeled cells were found in layers 5 or $6 . u w m$, White matter directly underlying layer 6 .

later. To address this question, one ferret was injected with ${ }^{3} \mathrm{H}$ thymidine on $\mathrm{E} 32$ and perfused on $\mathrm{P} 1$; an autoradiograph through its cerebral mantle is shown in Figure 10. Although the individual cortical layers could not be distinguished from one another at this age, it was clear that cells heavily labeled with ${ }^{3} \mathrm{H}$-thymidine were concentrated in the lower half of the cortical plate. Cells at the top of the plate, which represent the most recently arrived young neurons, were labeled only lightly, if at all. Thus, it seems likely that neurons generated on E32 arrive in the cortical plate well before $\mathrm{P} 1$, at which point they occupy their final laminar positions.

The corticogeniculate projection. The projection of normal neurons in layer 6 of area 17 to the LGN was studied after making geniculate injections of HRP or WGA in one normal ferret and in one ferret that had been injected with ${ }^{3} \mathrm{H}$-thymidine on E32 (see Table 2 for details). The purpose of these experiments was to characterize a major projection from the deep layers, in order to later be able to study the axonal connections of transplanted neurons. The corticogeniculate projection was chosen because, in the cat, roughly half of all cells in layer 6 project to the LGN (Gilbert and Kelly, 1975). Other projections from deep-layer neurons were not examined in this study; however, known targets of layer 5 and 6 cells in the cat include the superior colliculus, LP-pulvinar, pons, and the claustrum (Gilbert and Kelly, 1975; LeVay and Sherk, 1981; Katz et al., 1984). Furthermore, in the ferret a small number of deep-layer neurons contributes to the projection from area 17 to prestriate visual areas 18 and 19 (Fig. 7D).

A geniculate injection site in one ferret (no. 191) is shown in Figure $11 \mathrm{~A}$. This injection was centered at an azimuth of $18^{\circ}$ and elevation of $25^{\circ}$ in the A layers, but spread to involve the $\mathrm{C}$ layers as well. Patches of retrogradely labeled cells were observed in both areas 17 and 18 . Some of the labeled cells in area 17 (boxed region in Fig. $11 B$ ) are outlined in Figure $11 C$. HRPlabeled cells were found predominantly in the lower two-thirds of layer 6; occasional labeled cells in layer 5 and in the white matter directly underlying layer 6 were also observed. It is not clear whether the retrograde labeling of layer 5 cells was due to damage of axons of passage from other corticofugal projections (as suggested by McCourt et al., 1986) or whether there might in fact be a projection from layer 5 to the geniculate $C$ layers. It is unlikely that layer 5 cells project to the A laminae of the 
LGN, since WGA injections restricted to the A layers in the mink (another mustelid carnivore) result in retrograde labeling only in layer 6 (McConnell and LeVay, 1986).

Figure $11 \mathrm{C}$ also shows the positions of ${ }^{3} \mathrm{H}$-thymidine-labeled cells in the same section, since this animal had received an injection of ${ }^{3} \mathrm{H}$-thymidine on E32. Here, as noted previously, heavily labeled cells were found predominantly in layer 5 and in the upper two-thirds of layer 6 . Note that there is a small spatial mismatch between the populations of HRP- and ${ }^{3} \mathrm{H}$ thymidine-labeled cells, with the HRP-labeled neurons being the sole occupants of the bottom third of layer 6 . There is nevertheless, a region of overlap, and within this region several double-labeled cells are found; one of these is shown in Figure $11, D, E$. A fairly large proportion of layer 6 cells in the region shown are retrogradely labeled from the LGN (roughly $50 \%$ ), and about $10 \%$ of all neurons in layer 6 are labeled with ${ }^{3} \mathrm{H}$ thymidine. Thus the probability of finding double-labeled cells would theoretically be about 1 in 20 , a fraction roughly comparable to that observed.

\section{Development of cells in isochronic transplants}

The goal of the isochronic transplants was to develop a system in which newly generated cortical neurons could be transplanted into another brain, yet would still migrate into the cortical plate and differentiate in as normal a manner as possible. The following sections describe the initial labeling of donor cells (which allowed transplanted cells to be distinguished from host cells in the host brain), the developmental changes observed in the transplanted cells, and their final fates in adult host brains.

Labeling of cells prior to transplantation. The proliferative zone cells to be transplanted back into same-age hosts were labeled in 2 different ways: The first label, ${ }^{3} \mathrm{H}$-thymidine, served both as a permanent tag to show the donor origin of a transplanted cell and as a marker of the cell's birthday (and, thereby, its laminar destination in the normal animal). The second label was one of 2 fluorescent dyes, DAPI or fast blue, and was meant to mark all transplanted cells in the host brain, not just those that had undergone their final mitotic division following the ${ }^{3} \mathrm{H}-$ thymidine injection. The dye labels had the advantage that they could be visualized immediately using epifluorescence microscopy, whereas the radioactive marker required several weeks of autoradiographic processing in order to visualize labeled cells. The major disadvantage of the blue dyes was that, particularly in the case of fast blue (which is poorly soluble in aqueous solution), there were no guarantees that host cells could not pick up the dye label themselves. Thus, although the DAPI and fast blue labels were used to study the development of transplanted cells, the ${ }^{3} \mathrm{H}$-thymidine label was relied on as definitive proof of a transplanted cell's donor origin. (For evidence that host cells do not pick up detectable amounts of ${ }^{3} \mathrm{H}$-thymidine from the transplants, see Materials and Methods.)

Cells from the proliferative zone readily accumulated DAPI and fast blue from aqueous culture medium and became brightly labeled within $15 \mathrm{~min}$. Roughly comparable percentages of dissociated cells were labeled with DAPI $(76 \%)$ and fast blue $(69 \%)$. Samples of dissociated cells were allowed to attach to a polylysine-treated glass slide prior to fixation and processing for autoradiography; some of these are shown in Figure 12. The dissociated cells were small and round (usually about 3-5 $\mu \mathrm{m}$ in diameter), and about $30 \%$ of dye-labeled cells were also labeled with ${ }^{3} \mathrm{H}$-thymidine.

Development of dye-labeled cells following isochronic trans-

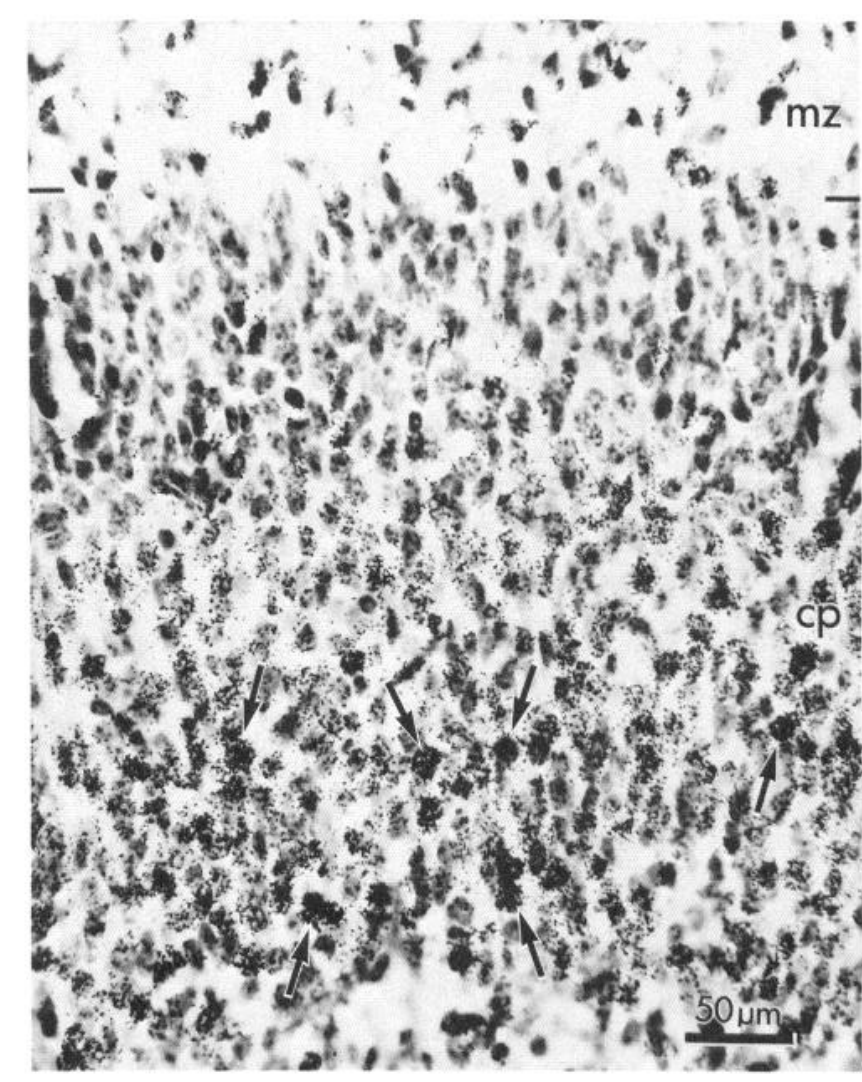

Figure 10. Bright-field autoradiograph through the marginal zone $(m z)$ and cortical plate $(c p)$ of a ferret on $\mathrm{Pl}$ following injection of ${ }^{3} \mathrm{H}$-thymidine on E32. The most heavily labeled cells (arrows) were found at the base of the cortical plate, and cells in the compact zone at the top of the cortical plate were lightly labeled, if at all.

plantation. The positions of dye-labeled cells at 3 different times following transplantation into a same-age host are reconstructed in Figure 13. An injection site, viewed after a $2 \mathrm{hr}$ survival, is shown in Figure 13A; the transplanted cells occupy a cigarshaped region centered in the proliferative zone that extends out into the lower intermediate zone. This shape does not represent spread along the pipette track, since the pipette would have entered the brain from the top of the section. Figure $14 \mathrm{~A}$ shows fluorescent cells found at such an injection site; they are small and round, resembling freshly dissociated cells in vitro.

Both the positions and morphologies of dye-labeled cells changed with time after transplantation. By $2 \mathrm{~d}$, fluorescent cells formed a radially oriented stream that extended well into the intermediate zone, and by $4 \mathrm{~d}$ (Fig. 13B), dye-labeled cells were found in all regions of the cerebral mantle, from the proliferative zone to the marginal zone. Although a variety of morphological types were observed, one type of transplanted cell was particularly striking. These cells were found in the intermediate zone and at the leading edge of cells entering the cortical plate. They had spindle-shaped nuclei and radially oriented leading processes (Fig. 14B); thus such cells resembled young cortical neurons migrating out to the cortical plate (Rakic, 1972). By 4-6 d after transplantation, dye-labeled cells that were found at the top of the cortical plate had lost their spindle shape; their nuclei were oval and often contained multiple nucleoli (not shown), which are characteristic of newly arrived neurons in the cortical plate (Shimada and Langman, 1970).

Figure $13 C$ shows the distribution of dye-labeled cells in a 

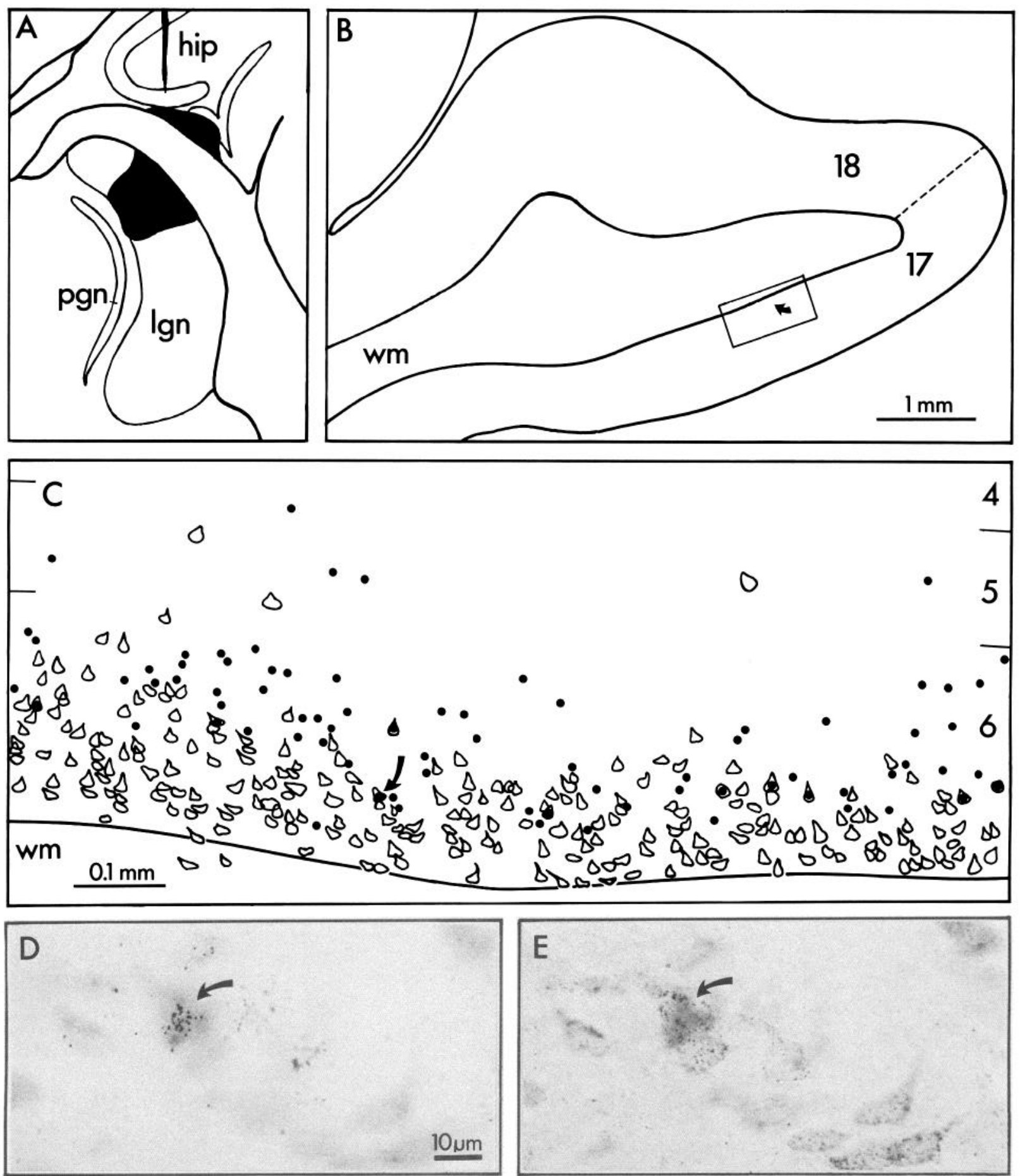

Figure 11. Results of an experiment in which an adult ferret that had received an injection of ${ }^{3} \mathrm{H}$-thymidine on E32 was given an injection of HRP into the lateral geniculate nucleus (lgn). A, Reconstruction of the injection site in the LGN, parasagittal view. $B$, Reconstruction of the ferret's visual cortex in the region of retrograde labeling in area 17. Posterior is to the right. Retrogradely labeled cells in a small region of area 17 (box) are reconstructed in $C$. Scale bar is for $A$ and $B$. Arrow points to the position of the double-labeled neuron shown in $D$ and $E$. $C$, Reconstruction of the positions of the neurons retrogradely labeled with HRP (outlined) or labeled with ${ }^{3} \mathrm{H}$-thymidine (dots) from the area boxed in $B$. Most HRPlabeled cells were in the bottom two-thirds of layer 6, although a few labeled cells were found in layer 5 as well. Most ${ }^{3} \mathrm{H}$-thymidine-labeled cells were found in layer 5 and 6 . Several cells (e.g., arrow) contained both labels. $D$, Neuron labeled with ${ }^{3} \mathrm{H}$-thymidine (arrow), focus on the plane of the silver grains overlying the cell's nucleus. $E$, Same neuron with plane of focus on the HRP reaction product in the cell's cytoplasm.

host animal $12 \mathrm{~d}$ after transplantation. Here, again, fluorescent cells were found in a radially oriented stream; however, at this age, 2 morphological classes of transplanted cells could be clearly distinguished. In the first group were cells that were apparently undergoing neuronal differentiation; they were found at the top of the cortical plate (arrows in Fig. 13C). Two such cells are shown in Figure 14, $D, E$; they have pyramidal cell bodies and apical dendrites that extend toward the marginal zone. Some 


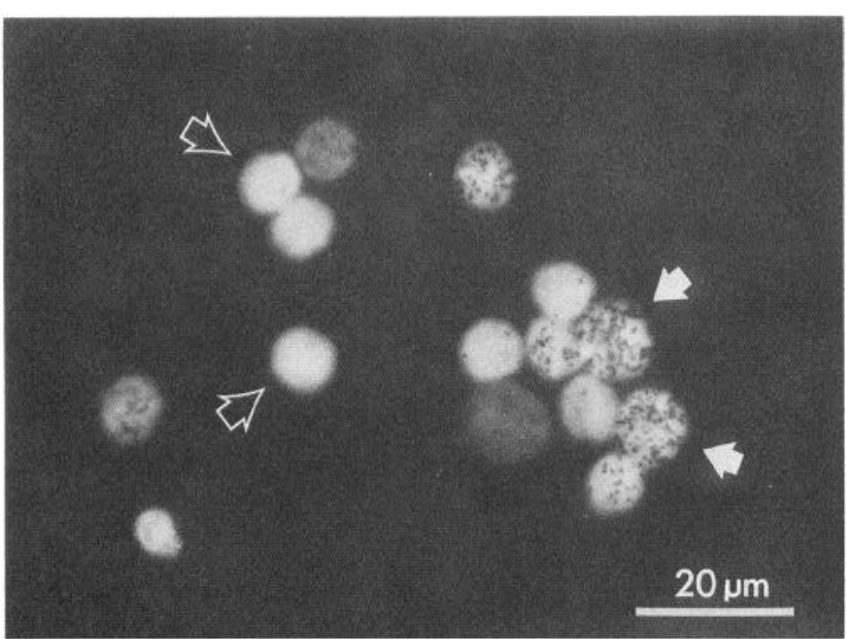

Figure 12. Cells from the proliferative zone of a newborn ferret that were labeled with ${ }^{3} \mathrm{H}$-thymidine and DAPI prior to dissociation. These cells were allowed to attach to a polylysine-coated surface prior to fixation and processing for autoradiography, and are here viewed with a combination of epifluorescent and bright-field illumination. Some cells show only the DAPI label (open arrows), while others are labeled with ${ }^{3} \mathrm{H}$-thymidine as well (solid arrows).

dendritic differentiation is even visible in the apical dendrite of one cell (arrow, Fig. 14D). The second class of dye-labeled cell was found in all layers of the host cerebral mantle, but was most common in the intermediate zone. These cells resembled glial cells in their morphology: they tended to have round or somewhat lobular cell bodies, and extended fine processes irregularly around them (Fig. 14C). Because of their resemblance to astrocytic glial cells (Vaughan, 1984), it was asked whether these dye-labeled cells were immunoreactive for GFA, a major intermediate filament protein of astrocytes (Bignami et al., 1972). Although many host cells showed GFA immunoreactivity, none of the dye-labeled cells did. (However, one such cell was doublelabeled in a heterochronic transplant; see Fig. 22, D, E.)

Transplanted cells labeled with ${ }^{3} \mathrm{H}$-thymidine. The ${ }^{3} \mathrm{H}$-thymidine label also appeared to distinguish between the neuronal class of transplanted cells and those that resembled glial cells. Surprisingly few cells were double-labeled with both the fluorescent dye and ${ }^{3} \mathrm{H}$-thymidine; apparently, in tissue sections those cells that are superficial enough in the section to show radioactive labeling (roughly the upper third of a $20 \mu \mathrm{m}$ section) contain too little dye-labeled cytoplasm to show fluorescent labeling (Stanfield and O'Leary, 1985b). However, when the positions of ${ }^{3} \mathrm{H}$-thymidine-labeled cells were plotted over time (Fig. 15), it became clear that their distribution reflected that of the neuronal class of cells and not of the whole population. This is as one would expect, given that few glial cells are labeled after long survivals following normal $\mathrm{P} 1{ }^{3} \mathrm{H}$-thymidine injections. Initially found at the injection site (Fig. $15 \mathrm{~A}$ ), the ${ }^{3} \mathrm{H}$-thymidinelabeled cells were located in the intermediate zone and cortical plate at 4-6 d after transplantation (Fig. 15B). Most labeled cells were found in the cortical plate by 2 weeks posttransplantation (Fig. 15C), in what resembled their final, adult distribution (Fig. $15 D$ ). The sequence and timing of these changes in position bore a marked similarity to those of normal postnatally generated cells labeled with ${ }^{3} \mathrm{H}$-thymidine (Fig. 6). Of course, in both cases, it seems unlikely that all cells initially labeled with ${ }^{3} \mathrm{H}$-thymidine on P1 and 2 were destined to become neurons,
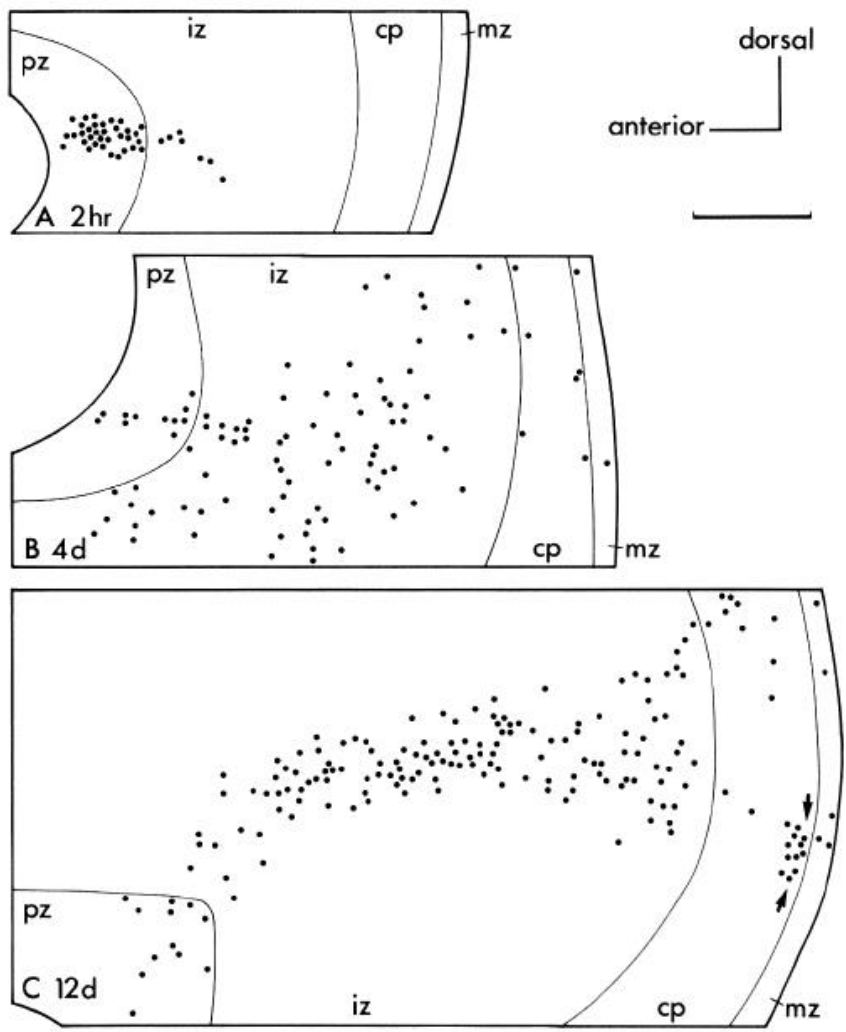

Figure 13. Reconstructions of the positions of dye-labeled, transplanted cells $($ dots $)$ in host brains at 3 different times after isochronic transplantation. $A$, Two hour survival, showing cells clustered at the injection site. $B$, After $4 \mathrm{~d}$, labeled cells were found in a stream reaching from the ventricular to pial surfaces. $C$, After $12 \mathrm{~d}$, cells were still found in a radial stream. Arrows delineate region in the cortical plate where dyelabeled cells with neuronal morphology were found. Scale bar $(A, B)$ $300 \mu \mathrm{m}$; (C) $500 \mu \mathrm{m}$. Abbreviations: $p z$, proliferative zone; $i z$, intermediate zone; $c p$, cortical plate; $m z$, marginal zone. (From McConnell, 1985; used with permission from American Association for the Advancement of Science.)

since many cells (including glia) that continued to divide would dilute out their radioactive label and thus effectively disappear. Clearly, however, those cells that retained this label had a distribution similar to that of the dye-labeled cells showing neuronal morphology.

Morphology of transplanted neurons after long survivals. The dyes DAPI and fast blue were retained by transplanted neurons for only about 1 and 3 weeks, respectively. The impression was that as the volume of transplanted cells increased with differentiation, the dyes were progressively diluted out. Transplanted cells that resembled glial cells, however, retained their dye labels for much longer periods (up to several months). Because of the short-term nature of the dye labeling, the ${ }^{3} \mathrm{H}$-thymidine label was used as a permanent marker of both a cell's donor origin and its birthdate.

In adult ferrets that had received isochronic transplants as neonates, the morphology of ${ }^{3} \mathrm{H}$-thymidine-labeled cells in Nisslstained sections resembled that of surrounding, unlabeled host neurons. Figure 16 shows 2 such cells in an animal several months after transplantation. The labeled cells have pyramidal cell bodies and apical dendrites extending toward the pial surface. All in all, the labeled cells are well-integrated into the host cortex and appear indistinguishable from the host neurons (except for their radioactive label). 

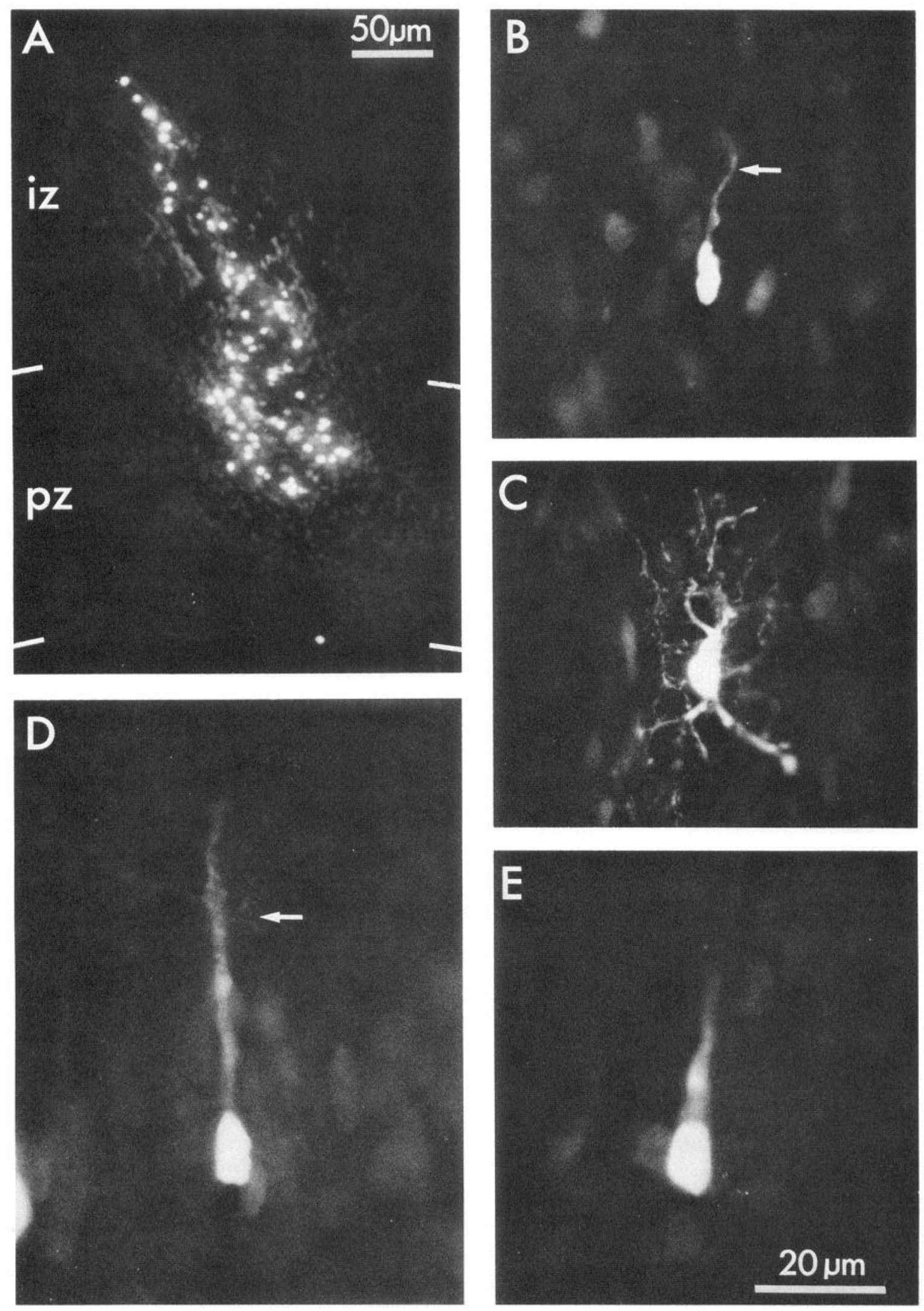

Figure 14. Fast blue-labeled cells after isochronic transplantation. $A$, Injection site showing small round cells in the proliferative zone ( $p z$ ) and lower intermediate zone $(i z) 2 \mathrm{hr}$ after transplantation. B, Migrating cell in the intermediate zone $4 \mathrm{~d}$ after transplantation. Arrow points to leading process. $C$, Dye-labeled cell with glial morphology in the intermediate zone $12 \mathrm{~d}$ after transplantation. $D$, Dye-labeled cell at the top of the cortical plate showing pyramidal neuronal morphology and some differentiation of its apical dendrite (arrow) $12 \mathrm{~d}$ after transplantation. $E$, Pyramidal transplanted neuron at the top of the cortical plate $12 \mathrm{~d}$ after transplantation. Scale bar $(E)$, for $B-E$. 

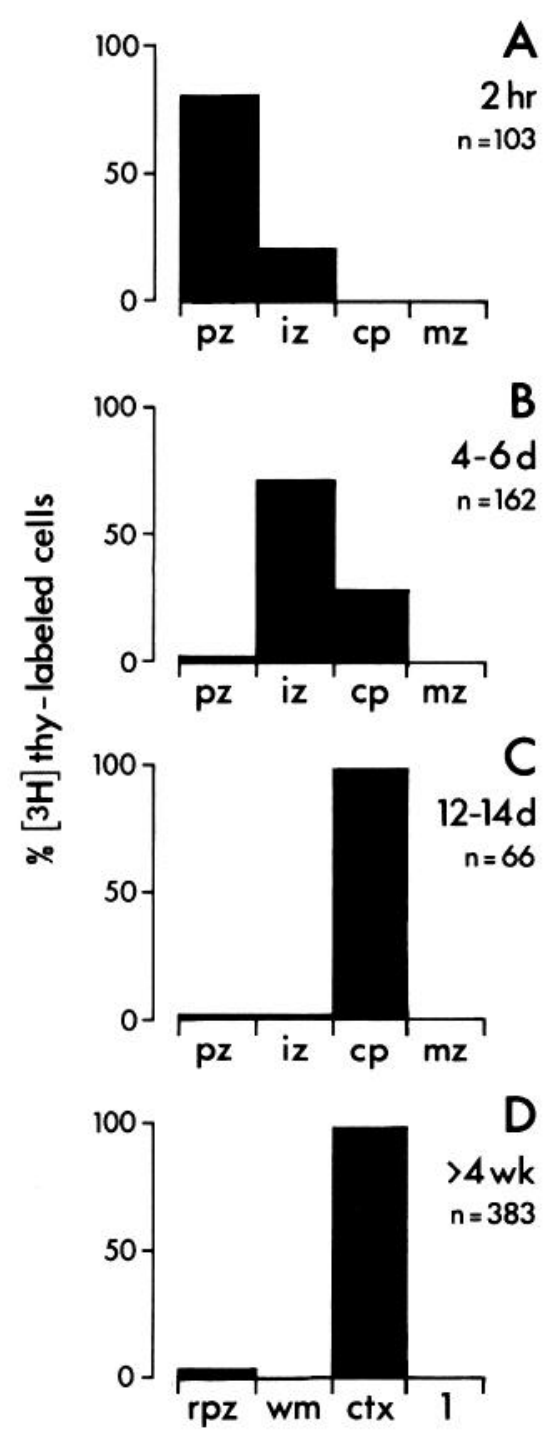

Figure 15. Distribution of ${ }^{3} \mathrm{H}$-thymidine-labeled cells throughout the cerebral mantle at 4 different times after isochronic transplantation. $A$, Cells at the site of injection in the proliferative zone $(p z)$ and lower intermediate zone ( $i z) 2 \mathrm{hr}$ after transplantation. B. After 4-6 d survival, labeled cells are found predominantly in the intermediate zone and cortical plate $(c p)$. $C$, After 12-14 d survival, most labeled cells are at the top of the cortical plate. $D$, Final positions of ${ }^{3} \mathrm{H}$-thymidine-labeled cells in mature hosts. About $97 \%$ of cells are in the cerebral cortex (ctx), and a few are seen in the remnant of the proliferative zone $(r p z)$. Abbreviations: $m z$, marginal zone; $w m$, white matter; 1 , layer 1 .

Final position of isochronically transplanted cells. The final laminar positions of several ${ }^{3} \mathrm{H}$-thymidine-labeled cells in an isochronic host brain, several months after transplantation, are reconstructed in Figure 17. All labeled cells in these sections are found in the peripheral visual-field representation of area 17, and all are in layer $2 / 3$, their normal destination. The transplanted cells in this case are distributed over what would probably be tens of degrees of visual space (estimated from studies of the mink; McConnell and LeVay, 1986); they certainly do not occupy a single cortical column. Rakic (1978) has proposed that there is a point-to-point matching between the ventricular and pial surfaces of the brain in normal development. In the present experiments, because the injected cells initially occupied a volume of the proliferative zone and not a single point, the

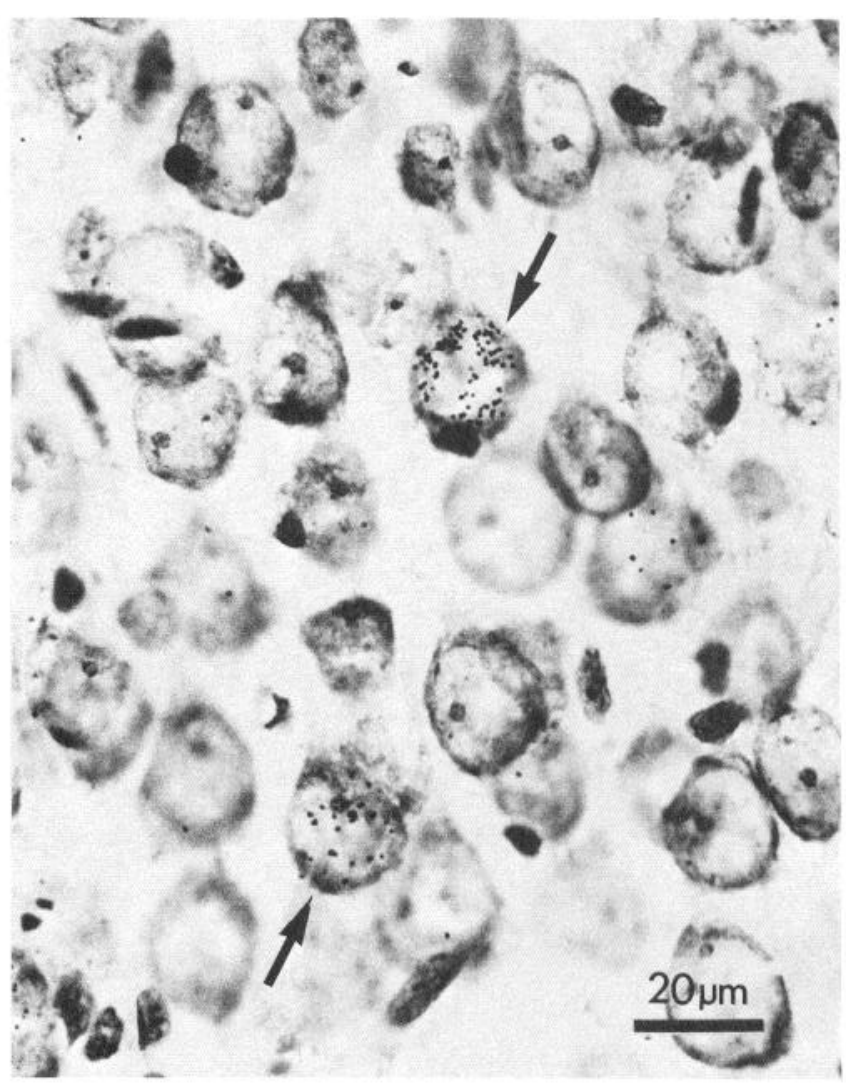

Figure 16. Nissl-stained autoradiograph from area 17, showing 2 isochronically transplanted neurons labeled with ${ }^{3} \mathrm{H}$-thymidine (arrows). Both have pyramidal cell bodies and apical dendrites. They are sitting in layer 2/3, 6 weeks after transplantation. (From McConnell, 1985; used with permission from American Association for the Advancement of Science.)

finding that the transplanted cells were spread out in the host cortex does not directly address Rakic's hypothesis.

The final laminar positions of all 383 radioactively labeled cells in isochronic transplants (recovered from 14 host ferrets from 8 litters) are plotted in histogram form in Figure 18. Overall, $97 \%$ of labeled cells were found in the cortex; the remaining $3 \%$ were in the remnant of the embryonic proliferative zone (where a small number of labeled cells was also found in normal adult ferrets injected with ${ }^{3} \mathrm{H}$-thymidine on $\mathrm{P} 1$; see Fig. 6). Within the cerebral cortex, all but 2 of the transplanted cells came to sit in layer $2 / 3$, the normal destination of postnatally generated cortical neurons. About $96 \%$ of the labeled cells in cortex were in area 17 , and the remaining $4 \%$ were in area SV.

Calculations of cell survival following transplantation are difficult to make, primarily because of uncertainties in calculating the precise number of cells that are transplanted (see Materials and Methods). Nevertheless, estimates were made on the basis of counts of ${ }^{3} \mathrm{H}$-thymidine-labeled cells from a 1 -in- 5 series of sections from each host brain. The counts were corrected to allow for the remaining sections and for the fact that only those cells in the upper third of each $20 \mu \mathrm{m}$ section are detected using autoradiography. On average, the corrected number of ${ }^{3} \mathrm{H}$-thymidine-labeled cells in a host brain was 410 (ranging, in successful transplants, from 60 to 1005). Each animal initially had from 2000 to 5000 cells transplanted into its brain; of these, theoretically $600-1500$ would have been labeled with ${ }^{3} \mathrm{H}$-thy- 


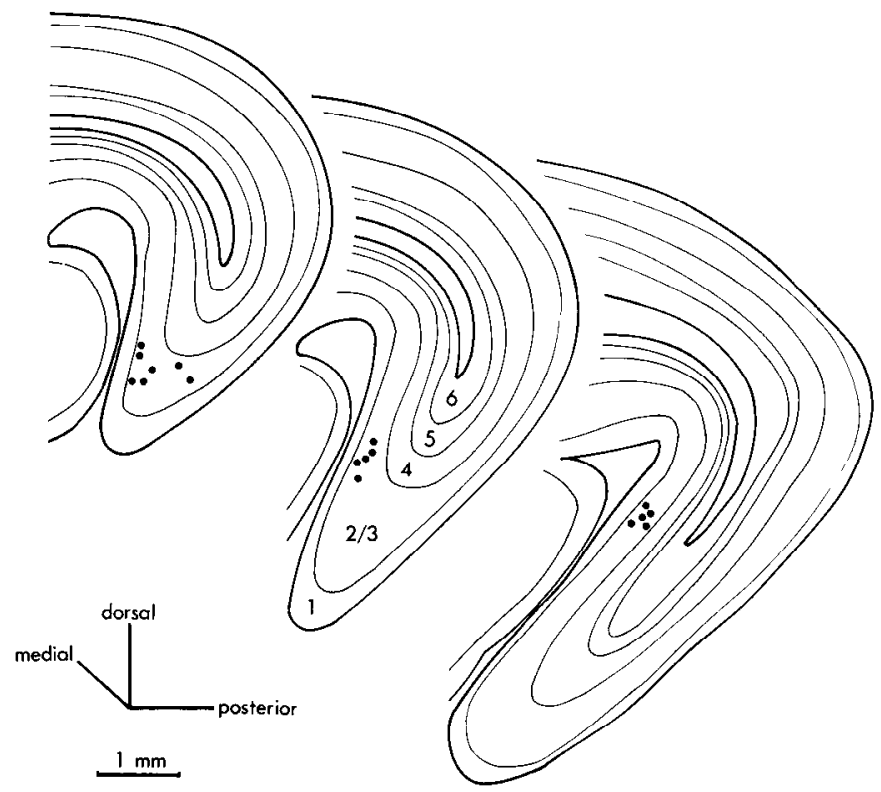

Figure 17. Reconstruction of 3 parasagittal sections through an isochronic host ferret brain, showing the positions of ${ }^{3} \mathrm{H}$-thymidine-labeled neurons (dots). Labeled cells were found in the peripheral visual-field representation of area 17, and all were in layer 2/3. (From McConnell, 1985; used with permission from American Association for the Advancement of Science.)

midine. Thus, these calculations allow a rough estimate of cell survival (or, more accurately, cell recovery) following transplantation; on average, about $36 \%$ of the expected number of ${ }^{3} \mathrm{H}$-thymidine-labeled cells was retrieved from host brains (range, $7-100 \%$ ). This figure is, of course, a minimum estimate of cell survival, since any ${ }^{3} \mathrm{H}$-thymidine-labeled cells that reentered the mitotic cycle after transplantation would have diluted out their radioactive label.

Axonal projections of transplanted neurons. Isochronically transplanted neurons adopted morphologies and laminar positions that are typical of normal, postnatally generated neurons in the ferret's visual cortex. Did these transplanted cells elaborate normal axonal projections as well? To address this question, HRP was injected into areas 18 and 19 of 8 ferrets that had received isochronic transplants as neonates. As described above, these areas are the recipients of a substantial projection from the upper layers of area 17 in the normal ferret.

The chances of finding a transplanted neuron that is also retrogradely labeled with HRP appear to be slim. First, even when a transplant is successful, the number of transplanted cells forms only a tiny fraction of neurons in the cortex. Second, HRP must be injected into the regions of area 18 and 19 in retinotopic correspondence to the region containing transplanted cells in area 17. (This problem was met by making multiple injections into these areas; however, it seems that the far periphery of the visual field may not even be represented in area 18.) And finally, as Figure 7 has demonstrated, even when ${ }^{3} \mathrm{H}$-thymidine- and HRP-labeled cells overlap in their spatial extent, the incidence of double-labeling is low.

In spite of these problems, 7 double-labeled cells in layer 2/ 3 of area 17 were recovered from 2 isochronic animals. Another 3 transplanted cells in layer $2 / 3$ of area SV were also retrogradely labeled with HRP in 2 other ferrets; the remaining 4 ferrets had no double-labeled cells. Figure 19 shows data from a successful

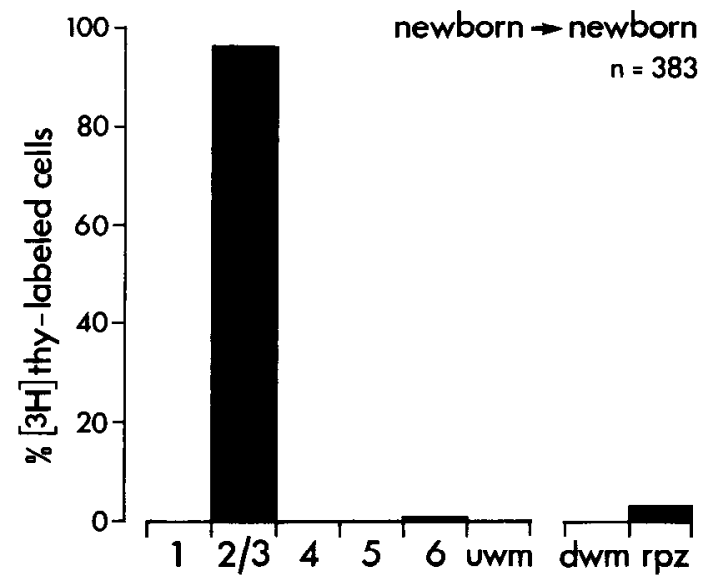

Figure 18. Final distribution of ${ }^{3} \mathrm{H}$-thymidine-labeled cells in host brains after isochronic transplantation. Roughly $97 \%$ of labeled cells were found in the visual cortex, and nearly all of these were in layer $2 /$ 3. About $3 \%$ of labeled cells were in the remnant of the proliferative zone $(r p z)$ near the lateral ventricle. Abbreviations: $u w m$, white matter directly underlying layer $6 ; d w m$, deep white matter.

experiment (ferret no. 169): part of the injection site in areas 18 and 19 is reconstructed in Figure $19 A$, and cells retrogradely labeled with HRP from a region of area 17 (box in Fig. 19A) are outlined in Figure 19D. One of these neurons is also labeled with ${ }^{3} \mathrm{H}$-thymidine (arrow in Fig. 19D). Figure 19, $B, C$, shows each of the labels contained by this transplanted pyramidal neuron.

While it was not tested whether transplanted neurons in the upper layers send axonal projections to any other normal (e.g., callosal) or abnormal (e.g., LGN) targets, it does seem clear that at least some are capable of forming projections to prestriate cortical areas, which are among their normal targets.

\section{Development of cells in heterochronic transplants}

In heterochronic transplants, cells from the proliferative zone of donor ferret embryos were transplanted back into the proliferative zone of a newborn host ferret. As with isochronic transplants, transplanted cells could be recognized by virtue of either their radioactive or dye label. When the latter was used to follow the early development of transplanted cells, it was found that a subpopulation of dye-labeled cells appeared to migrate into the cortical plate and differentiate into young cortical neurons, while many other dye-labeled cells developed morphologies resembling those of glial cells.

Two major differences emerged between the isochronic and heterochronic transplants when the final distribution of ${ }^{3} \mathrm{H}$-thymidine-labeled cells (which form a subpopulation of the dyelabeled cells) was examined. First, many radioactively labeled cells failed to migrate in the host brain and were found in ectopic clusters ncar the lateral ventricle. The sccond difference was seen in the laminar distribution of labeled cells that did migrate to the visual cortex. The following sections describe these results in greater detail, discussing first the distribution and morphologies of dye-labeled cells, and then turning to the position, morphology, and connections of the subpopulation of transplanted cells labeled with ${ }^{3} \mathrm{H}$-thymidine.

Development of dye-labeled cells following heterochronic transplantation. Figure 20 is a reconstruction of the positions 

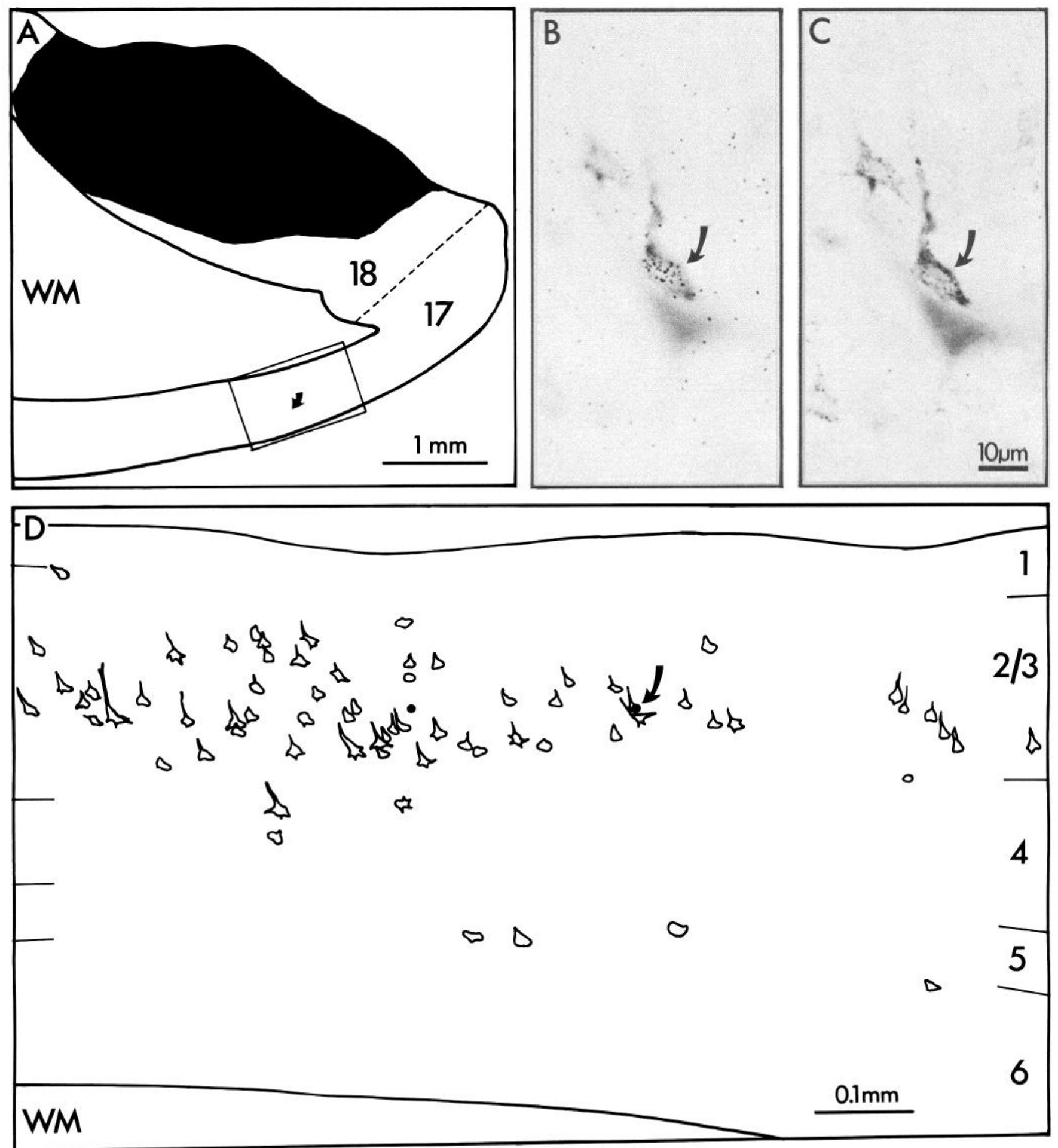

Figure 19. Results of an isochronic transplant in which the host also received HRP injections into areas 18 and 19. A, Reconstruction of a section showing injection sites in areas 18 and 19. Posterior is to the right. Retrogradely labeled cells were found in area 17, of which a small region (box) is drawn in D. Arrow points to a transplanted neuron that was also labeled with HRP. $B,{ }^{3} \mathrm{H}$-thymidine-labeled, transplanted neuron in area 17 ; plane of focus is on silver grains overlying the cell's nucleus. $C$, Same pyramidal neuron, plane of focus on the HRP reaction product in the cell's cytoplasm. $D$, Reconstruction of the boxed area in $A$, showing HRP-labeled neurons (outlined) in layer $2 / 3$ and at the $5 / 6$ border, and $2{ }^{3} \mathrm{H}$ thymidine-labeled, transplanted cells (dots). One of these is double-labeled (arrow).

of dye-labeled cells at 3 different times after transplantation. An injection site ( $2 \mathrm{hr}$ after transplantation) is shown in Figure $20 \mathrm{~A}$. Dye-labeled cells are clustered in the proliferative zone. In other injections, cells often were found at the base of the intermediate zone as well. As in isochronic transplants, cells at this time resembled freshly dissociated cells; they were small and round, with little cytoplasm (Fig. 21 A).

Both the position and morphology of heterochronically trans- 

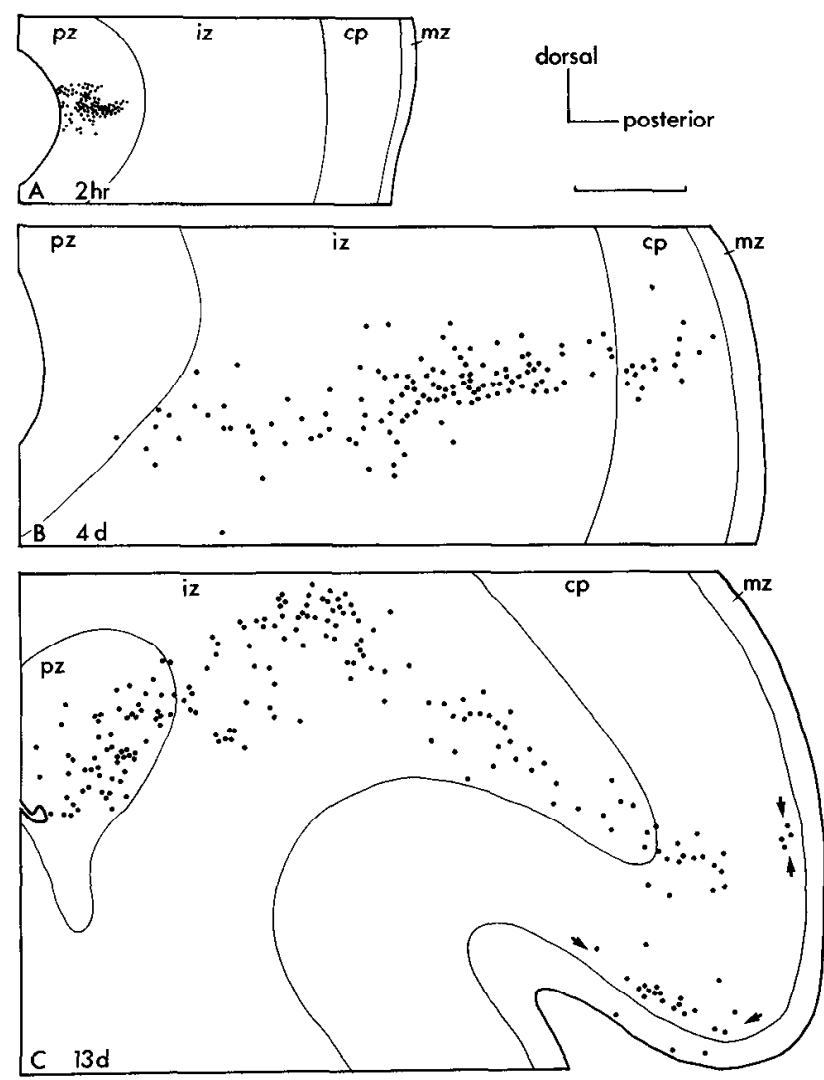

Figure 20. Reconstructions of the positions of dye-labeled transplanted cells $($ dots $)$ at 3 different times after heterochronic transplantation. Posterior is to the right. $A$, After a $2 \mathrm{hr}$ survival, dye-labeled cells were clustered at the injection site. $B$, After $4 \mathrm{~d}$, labeled cells formed a stream reaching from the proliferative zone $(p z)$ to the cortical plate $(c p)$. $C$, After $13 \mathrm{~d}$, cells were still found in a radial stream. Arrows delineate regions in the cortical plate where dye-labeled cells with neuronal morphologies were found. (The gap in the middle was filled in by another section; there were not 2 separate foci of migration, but rather one that terminated rather diffusely.) $B$ and $C$ are montages constructed from 2 and 3 closely spaced sections, respectively. Scale bar $(A, B) 300 \mu \mathrm{m},(C)$ $500 \mu \mathrm{m}$. Abbreviations: $i z$, intermediate zone; $m z$, marginal zone.

planted cells changed over time after the injection. Between 2 and $6 \mathrm{~d}$ after transplantation, dye-labeled cells were found in a radially directed stream that extended progressively closer to the pial surface with time. A reconstruction of the positions of dye-labeled cells after a $4 \mathrm{~d}$ survival is shown in Figure 20. Many of the cells at the "leading edge" of the stream, in the upper intermediate zone and the cortical plate, have morphologies characteristic of migrating cortical neurons, with elongated nuclei and leading processes directed radially toward the pial surface (Shimada and Langman, 1970; Rakic, 1972). Several of these dye-labeled cells in the intermediate zone are shown in Figure $21 \mathrm{~B}$, and Figure $21 \mathrm{C}$ shows a migrating cell in the cortical plate.

After a 13 d survival (Fig. 20C), dye-labeled cells were found in a stream extending through all layers of the cerebral mantle. Cells with clearly neuronal morphologies were found near the top of the cortical plate (arrows in Fig. 20C), and had pyramidal or oval bodies and radial apical dendrites. Two such young, transplanted neurons are shown in Figure 21, $D, E$.

As in isochronic transplants, the majority of dye-labeled cells developed morphologies that were more glial than neuronal in appearance (Fig. 22). These cells were found in all regions of the cerebral mantle, but most commonly in the intermediate zone. The cell shown in Figure $22 B$ is from an animal $13 \mathrm{~d}$ after heterochronic transplantation, and shows many of the characteristic features of this group of cells. They tended to have round nuclei and multiple, fine processes that radiated irregularly from the cell body. Figure $22 A$ shows what appears to be a similar cell just beginning to differentiate, $4 \mathrm{~d}$ after transplantation: it has a round cell body and extends several processes that end in clublike appendages. It was suggested in the isochronic results that, because of their positions and morphologies, these dyelabeled cells seem likely to be young astrocytes. Two pieces of evidence from these heterochronic transplants have strengthened this suggestion: first, several dye-labeled cells located at the base of the intermediate zone were found to extend long processes radially toward both the ventricular and pial surfaces of the host brain. The cell shown in Figure $22 C$ has processes (arrows) that could be followed for several hundred microns. These cells bear a striking resemblance to radial glial cells, which are astrocytic precursors (Schmechel and Rakic, 1979). A second, more direct piece of evidence is the dye-labeled cell shown in Figure 22, $D, E$, which was immunoreactive for GFA, the major intermediate filament protein of astrocytes (Bignami et al., 1972). This particular cell was, howcver, the exception rather than the rule in attempts to double-label these putative glial cells; perhaps the fast blue used to mark the cells prior to transplantation interferes with the access of anti-GFA antibodies to their antigen.

Pattern of ${ }^{3} \mathrm{H}$-thymidine labeling. In both types of transplants, cells labeled with ${ }^{3} \mathrm{H}$-thymidine represented a subpopulation of the total transplanted cells (most of which were dye-labeled). In isochronic transplants, the pattern of ${ }^{3} \mathrm{H}$-thymidine labeling was shown to further differentiate the neuronal and glial transplanted cells, since only young neurons bore the radioactive marker. A similar analysis in the heterochronic transplants, however, revealed the first striking difference from the isochronic results. Figure 23 outlines the pattern of movement of ${ }^{3} \mathrm{H}$-thymidinelabeled cells in heterochronic transplants at various times after transplantation. These histograms show that the great majority of radioactively labeled cells remained in the proliferative and intermediate zones (Fig. 23, B, C), and only a minority (about $20 \%$ ) eventually made their way into the cortical plate (Fig. $23 D$ ). Examination of histological sections revealed that the labeled cells that failed to migrate remained clustered together, and did not spread out through the cerebral mantle. These clusters most likely represented the original injection sites; thus the variability in the proportions of cells found in the proliferative and intermediate zones in Figure 23 probably reflects a variability in the exact positioning of injections rather than an actual movement of cells. Furthermore, ${ }^{3} \mathrm{H}$-thymidine-labeled cells in the cortex were always separated in space from the laggard clusters by distances of up to several millimeters (this can be seen more clearly in Fig. 24, discussed below), which supports the interpretation that the final positions of cortical neurons were achieved by an active migration rather than by passive deposition.

There is also a distinction to be made between the dye-labeled putative glial cells and those cells labeled with ${ }^{3} \mathrm{H}$-thymidine. Whereas the ${ }^{3} \mathrm{H}$-thymidine-labeled cells that failed to migrate were found in compact clusters, the dye-labeled cells with glial morphologies were found throughout the cerebral mantle (see Fig. 20C), as well as in the clusters. Because very few dye-labeled 

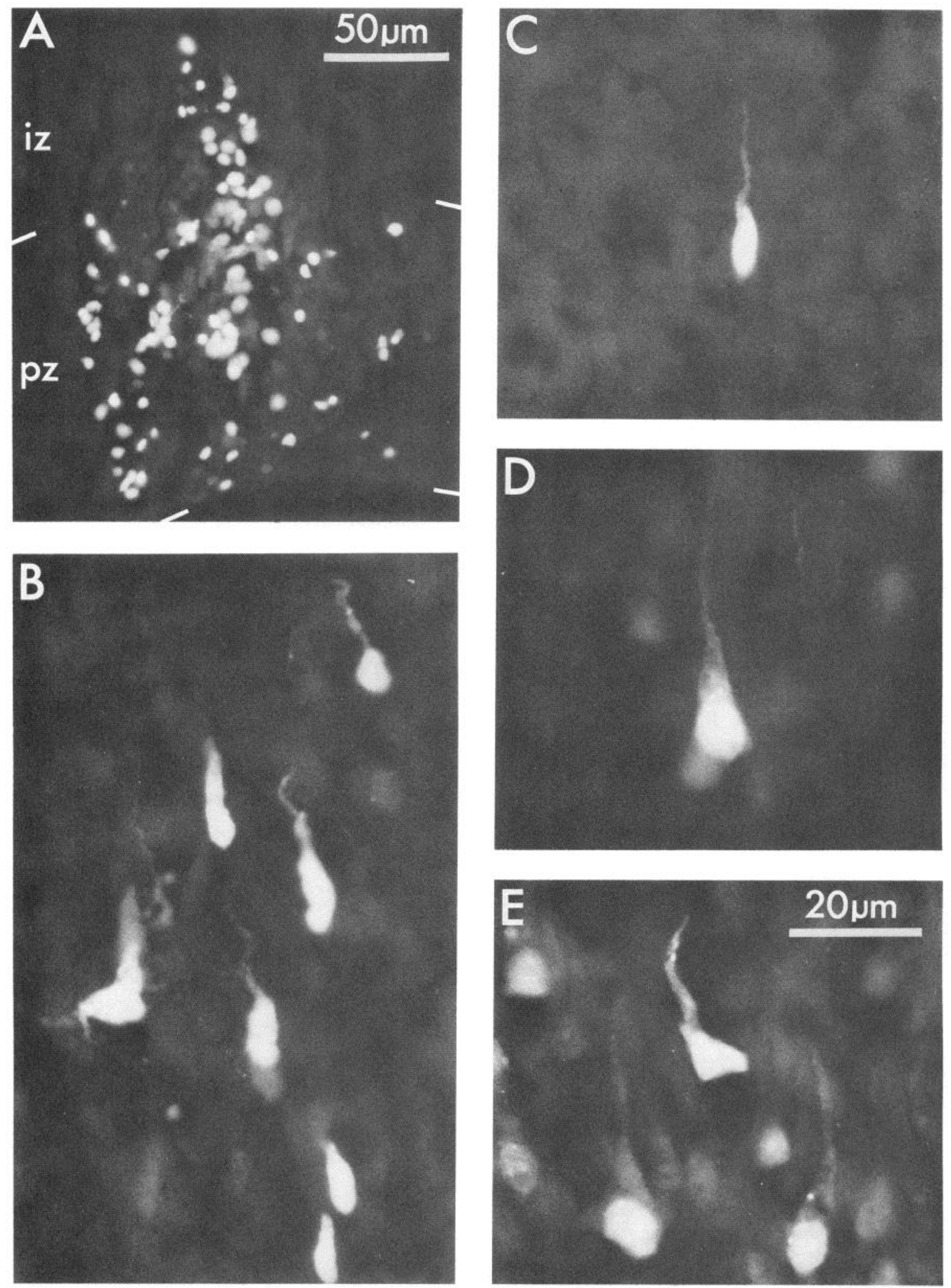

Figure 21. Fast blue-labeled cells with neuronal morphology at various times after heterochronic transplantation. $A$, Injection site showing small round cells clustered in the proliferative zone $(p z)$ and intermediate zone $(i z) 2 \mathrm{hr}$ after transplantation. $B$, Several migrating dye-labeled cells in the intermediate zone $4 \mathrm{~d}$ after transplantation. $C$, A migrating cell in the middle of the cortical plate. This cell was at the leading edge of the stream of cells headed into the cortical plate $4 \mathrm{~d}$ after transplantation. $D, E$, Dye-labeled cells with pyramidal cell bodies at the top of the cortical plate $13 \mathrm{~d}$ after transplantation. Scale bar, for $B-E$. 

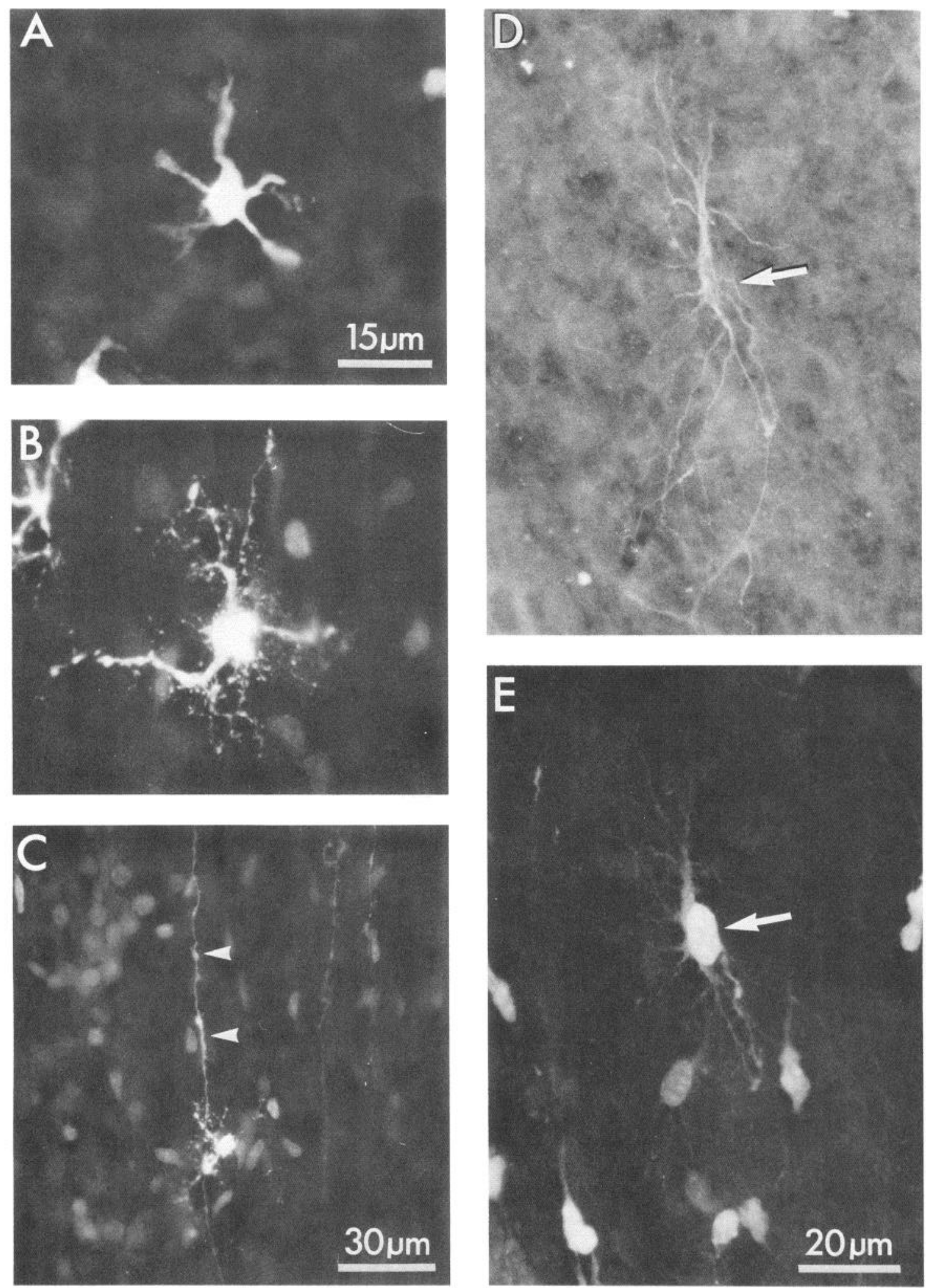

Figure 22. Fast blue-labeled cells with glial morphology at various times after heterochronic transplantation. $A$, Cell in the intermediate zone with round cell body and processes that end in blunt, clublike appendages, seen $4 \mathrm{~d}$ after transplantation. This cell appears to be just beginning its differentiation into a morphology like that in $B$. Scale bar, for $A$ and $B$. $B$, Dye-labeled cell in the intermediate zone with multiple, fine processes $13 \mathrm{~d}$ after transplantation. $C$, Dye-labeled cell with cell body at the base of the intermediate zone near the subventricular zone $13 \mathrm{~d}$ after transplantation. This cell has many small fine processes and also long radial processes (arrowheads) that stretch toward both the ventricular and pial surfaces. $D$, Cell in the intermediate zone (arrow) showing positive immunoreactivity for glial fibrillary acidic protein (GFA) under rhodamine epifluorescence. $E$, Same cell (arrow) is labeled with fast blue, seen $13 \mathrm{~d}$ after the transplantation. 

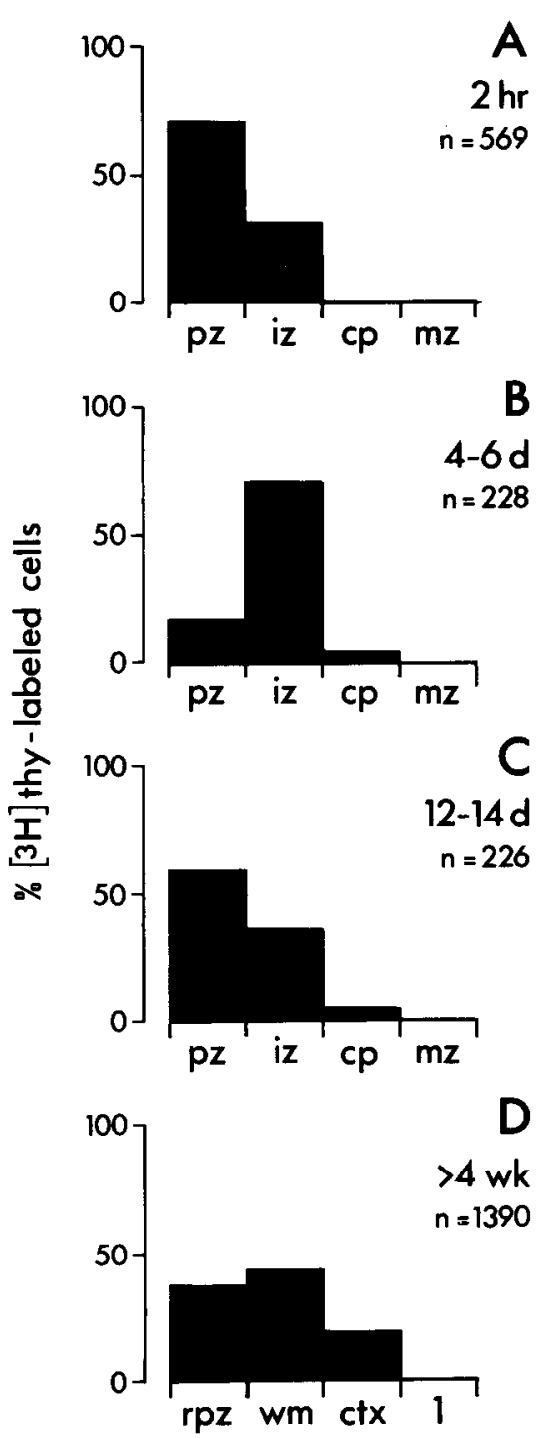

Figure 23. Distribution of ${ }^{3} \mathrm{H}$-thymidine-labeled cells throughout the cerebral mantle at 4 different times after heterochronic transplantation. $A$, Cells at the injection site in the proliferative zone $(p z)$ and intermediate zone $(i z) 2 \mathrm{hr}$ after transplantation. $B$, A few labeled cells are in the cortical plate 4-6 d after transplantation, but most remain in the proliferative and intermediate zones. $C$, After $12-14$ d survival, ${ }^{3} \mathrm{H}-$ thymidine-labeled cells remain distributed throughout the cerebral mantle. $D$, Final positions of ${ }^{3} \mathrm{H}$-thymidine-laheled cells in mature hosts. About $80 \%$ were in the remnant of the proliferative zone $(r p z)$ and deep in the white matter $(w m)$, where they remained clustered together. About $20 \%$ were found in the visual cortex $(c t x)$, though none were in layer 1 .

cells also show ${ }^{3} \mathrm{H}$-thymidine labeling because of technical factors (Stanfield and O'Leary, 1985b), it was not possible to see directly whether any of the putative glial cells were radioactively labeled as well. Although these 2 populations overlapped in the region of the original injection site, it seems at least to be clear that many dye-labeled cells with glial morphologies outside this region were not labeled with ${ }^{3} \mathrm{H}$-thymidine.

Final positions of ${ }^{3} \mathrm{H}$-thymidine-labeled cells in heterochronic transplants. The ${ }^{3} \mathrm{H}$-thymidine label was used to identify transplanted cells after long survival periods ( $>4$ weeks). A reconstruction of the positions of labeled cells in 3 sections through one heterochronic host brain is shown in Figure 24. Two features are of note. First, as was mentioned above, a large number of

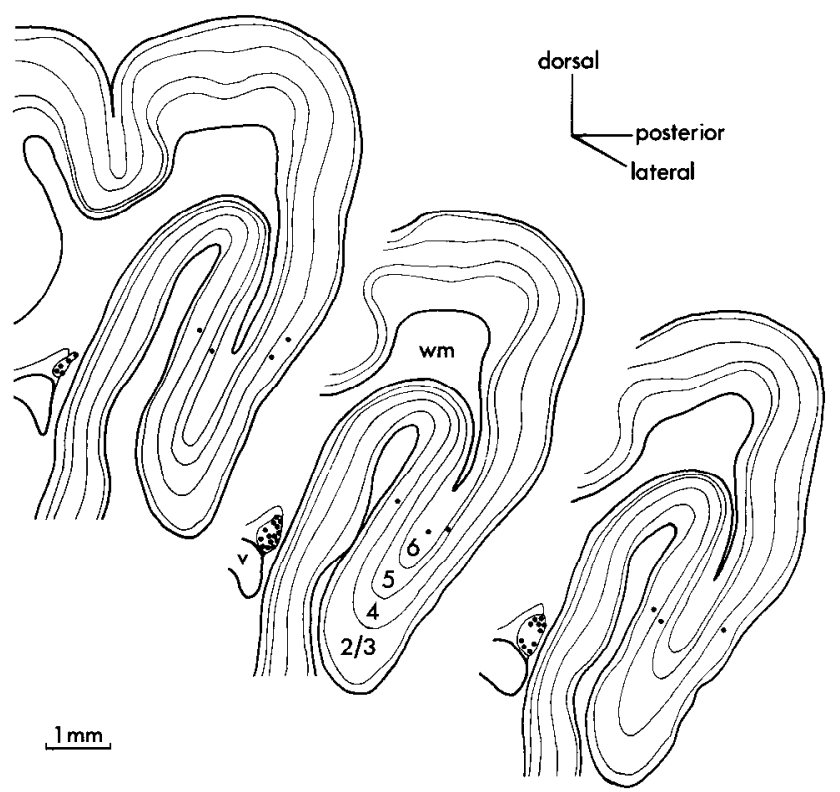

Figure 24. Reconstruction of 3 parasagittal sections through a heterochronic host brain, showing the positions of ${ }^{3} \mathrm{H}$-thymidine-labeled cells (dots). Many labeled cells were found clustered near the lateral ventricle (v). Other cells were in the peripheral visual-field representation of area 17 , where they were found in all cortical layers except layer 1.

${ }^{3} \mathrm{H}$-thymidine-labeled cells are seen to be clustered in a pocket or island sitting in the remnant of the embryonic proliferative zone, adjacent to the lateral ventricle. In other animals, these clusters could also be found buried deep in the white matter, lying between the ventricle and area 17 . It was common to see 2 small islands of labeled cells, one near the ventricle and the other in the white matter, connected to one another by a streak of labeled cells, as if their initial formation had been pulled and stretched by the growth and folding of the cerebral cortex. Islands of cells were recognizable in Nissl-stained sections even without the autoradiographic label. They contained cells of all sizes, some rather large, and many with morphologies that appeared quite neuronal (Fig. $25 F$ ). The interpretation has already been offered that these ectopic clusters of cells represent the original injection site; the identity and nature of the constituent cells are unclear, but several possibilities are considered in the Discussion.

The second, and most interesting, feature in Figure 24 is the distribution of heterochronically transplanted cells in the visual cortex. The ${ }^{3} \mathrm{H}$-thymidine-labeled cells in these 3 sections are found in all the cortical layers (except layer 1), and this widespread laminar distribution is characteristic of all animals that received heterochronic transplants. As in isochronic transplants, labeled cells are also spread out in their tangential extent over tens of degrees of the visual representation in area 17.

Morphology of heterochronically transplanted neurons. The impression gained from these studies was that the morphological appearance of ${ }^{3} \mathrm{H}$-thymidine-labeled neurons was similar to that of other cells sitting in the same layer, as far as could be judged from Nissl-stained sections. Examples of labeled cells from each layer are shown in Figure 25; these include a large pyramidal neuron at the base of layer $2 / 3$ (Fig. $25 A$ ), a smaller round cell in upper layer 4 (Fig. $25 B$ ), a medium-sized pyramidal cell in layer 5 (Fig. 25C), and a small neuron with an oval cell body in layer 6 (Fig. 25D). Labeled cells in the white matter directly 

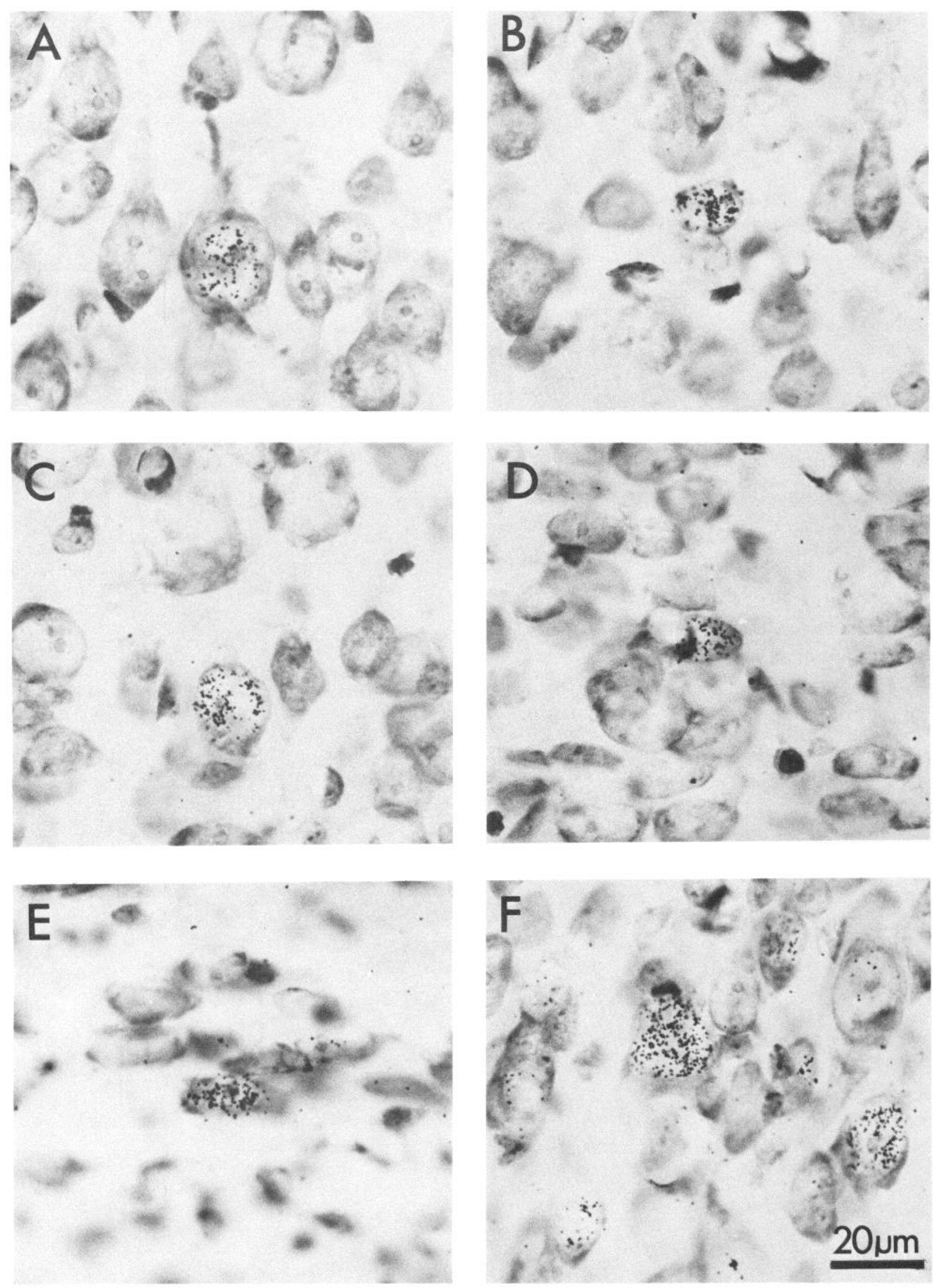

Figure 25. Nissl-stained autoradiographs in area 17 , showing ${ }^{3} \mathrm{H}$-thymidine-labeled neurons in each of the cortical layers following heterochronic transplantation. $A$, Large pyramidal neuron at the base of layer $2 / 3$. $B$, Smaller neuron with round cell body at the top of layer 4 . $C$, Medium-sized pyramidal neuron in layer $5 . D$, Small cell with oval cell body in layer 6 . The labeled neuron is sitting over an endothelial cell, which somewhat obscures the neuron's morphology. $E$, Horizontally elongated labeled cell in the white matter directly underlying layer $6 . F$, Labeled cells in cluster buried deep in the white matter. Many cells in such clusters have neuronal morphologies. 


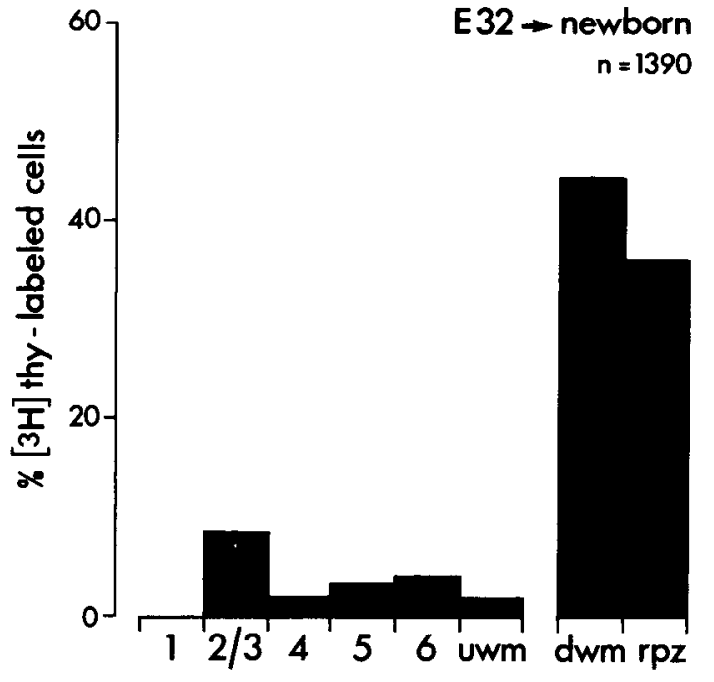

Figure 26. Final distribution of ${ }^{3} \mathrm{H}$-thymidine-labeled cells in host brains after heterochronic transplantation. Roughly $80 \%$ of labeled cells remained at their injection sites and were clustered together deep in the white matter $(d w m)$ or in the remnant of the proliferative zone $(\mathrm{rpz})$. The remaining $20 \%$ were distributed throughout the layers in the visual cortex. $u w m$, White matter directly underlying layer 6 .

below layer 6 showed hoizontally-oriented morphologies (Fig. $25 E$ ), similar in appearance to the interstitial neurons described in the monkey (Kostovic and Rakic, 1980) and cat (Luskin and Shatz, 1985b).

Laminar distribution of ${ }^{3} \mathrm{H}$-thymidine-labeled cells. The overall distribution of the positions of labeled cells in heterochronic host brains is shown in Figure 26. Of the 1390 cells counted from a 1-in-5 series of sections from each animal (12 ferrets from 5 litters), $80 \%$ are found in the ectopic clusters of cells buried deep in the white matter, or in the remnant of the proliferative zone, near the lateral ventricle. The remaining $20 \%$ are distributed throughout the layers of the visual cortex; of these, $93 \%$ are found in area 17 , and $7 \%$ in area SV adjacent to area 17. Although calculations of cell survival in these transplants are subject to several caveats, such estimates were made using the same methods applied to the isochronic transplants. The average recovery rate was $70 \%$, roughly twice that seen in isochronic transplants. This difference may have been due either to an enhanced ability of younger, embryonic tissue to survive following transplantation (Gash et al., 1985) or to the fact that fewer cells diluted out their ${ }^{3} \mathrm{H}$-thymidine label by mitotic divisions after heterochronic transplantation.

In order to compare the laminar distribution of ${ }^{3} \mathrm{H}$-thymidinelabeled cells in the visual cortex after heterochronic transplantation to that seen in the control isochronic transplants, the positions of cortical labeled cells from each case are replotted in Figure 27 . In isochronic transplants, $99 \%$ of the transplanted neurons in the cortex are found in layer $2 / 3$, their normal destination (Fig. 27A). The heterochronic distribution differs markedly (Fig. $27 B$ ): $43 \%$ of labeled cortical cells are in layer $2 / 3$, and the remaining $57 \%$ are distributed among the deeper layers. Layers 5 and 6 together account for $38 \%$ of the labeled cells; these layers are the normal laminar destination of the majority of cells generated on E32.

One interpretation of these results is that, in heterochronic transplants, a subpopulation of ${ }^{3} \mathrm{H}$-thymidine-labeled cells migrated selectively to the deep cortical layers to take up residence

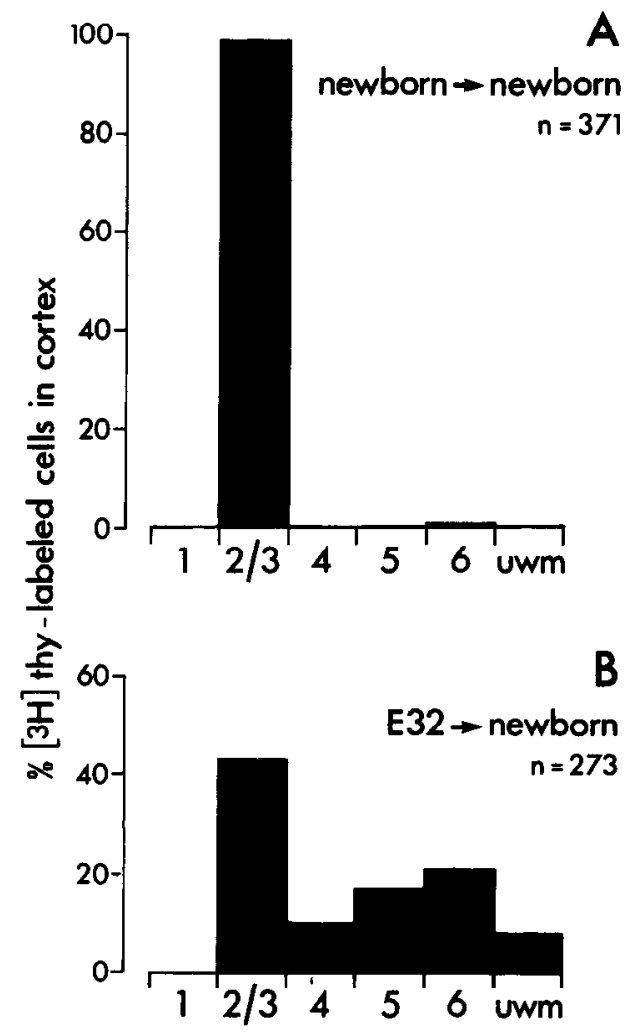

Figure 27. The final distribution of ${ }^{3} \mathrm{H}$-thymidine-labeled cells in visual cortex for isochronic and heterochronic transplants. Data are replotted from Figure 18 for $A$, and from Figure 26 for $B$. $A$, In isochronic transplants, all but 2 labeled cells were found in layer $2 / 3$. $B$, In heterochronic transplants, about $43 \%$ of labeled cells were in layer $2 / 3$, and the rest were distributed among the deeper layers. Layers 5 and 6 were the next most highly populated layers. $u \mathrm{wm}$, White matter directly underlying layer 6 .

in their normal laminar positions. An alternative explanation might be that in these transplants, labeled neurons distributed themselves randomly among the cortical layers. It seems unlikely that the latter was the case, because a random distribution could not predict the bimodal shape of the histogram in Figure $27 B$, regardless of whether cells were found randomly as a function of absolute depth in the cortex or in proportion to the cell density within a layer. Both versions fail to account for the relatively small proportion of labeled cells that ended up in layer 4 (a cell-dense layer). Given the tight laminar clustering of isochronic cells in the control transplants, the heterochronic results suggest that a subpopulation of presumptive deep-layer neurons were committed to their laminar fate prior to transplantation. Another substantial fraction of cells appeared uncommitted: they migrated along with host neurons to layer $2 / 3$ of the cortex, apparently following environmental directions or cues. Why the entire population of embryonically generated cells did not behave in a unified manner is not at all clear.

It is worth noting that, in normal ferrets, neurons generated on E32 do not come to occupy layers 5 and 6 exclusively -in fact, roughly $15 \%$ of these neurons are found superficial to the deep layers. Thus, some of the upper-layer neurons in heterochronic transplants may represent cells that have indeed achieved their normal fates. However, comparison of the laminar distributions of ${ }^{3} \mathrm{H}$-thymidine-labeled neurons in normal ferrets (Fig. 9) and in heterochronic transplants (Fig. 27B) reveals both qual- 

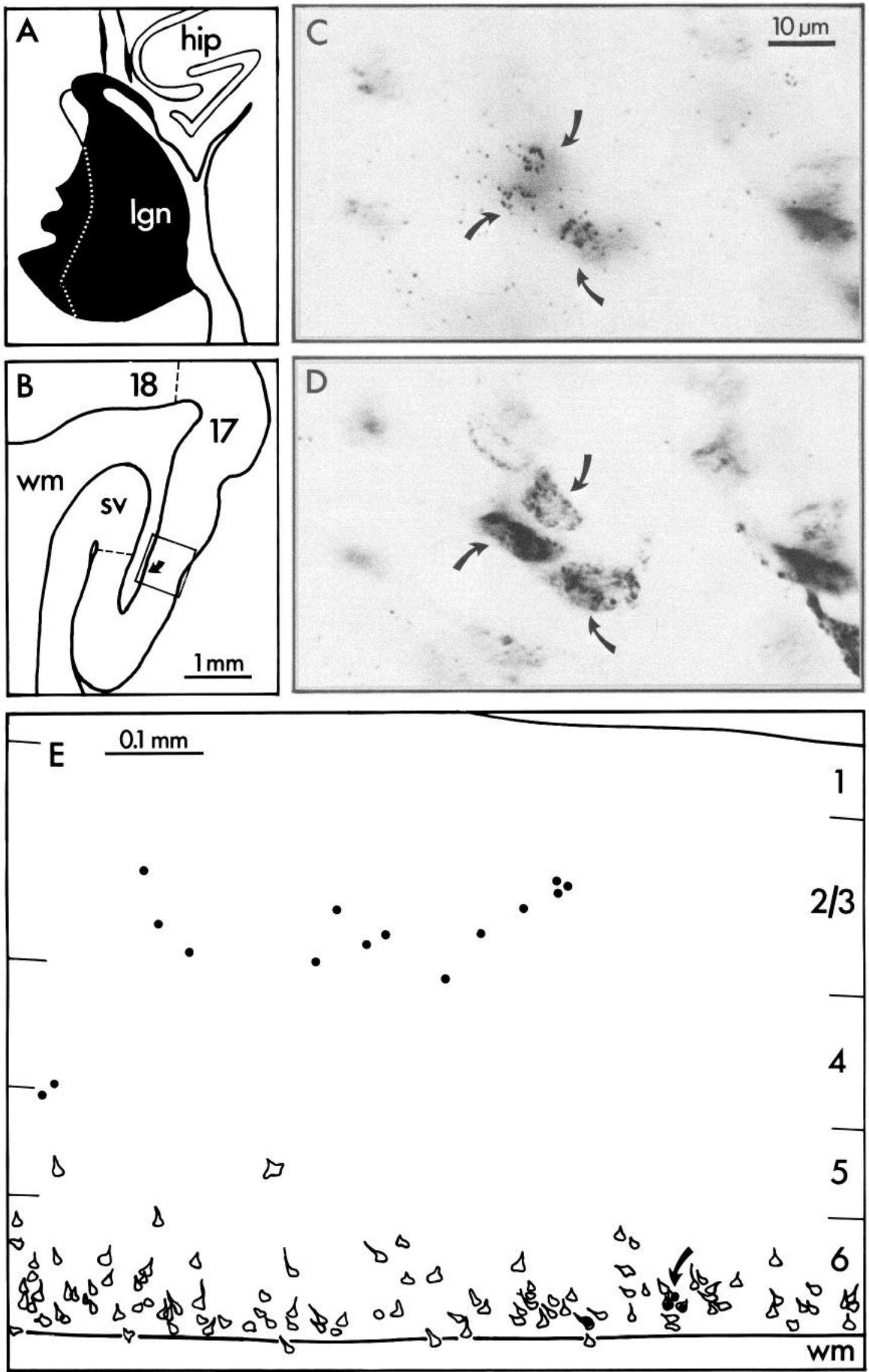
itative differences in the shapes of the histograms and quite substantial quantitative differences in the number of upper-layer cells found. It thus seems unlikely that this explanation is sufficient to account for the presence of large numbers of labeled cells in the upper layers of heterochronic transplants, and that, for many cells, this represents an abnormal laminar position.

Axonal projections of heterochronically transplanted neurons. The next issue considered was whether the heterochronically transplanted neurons formed axonal projections that were typical of their birthday. In light of work done in the reeler mouse mutant showing that cortical neurons can form connections typical of their birthdates regardless of the laminar positions (Caviness, 1976, 1982; Dräger, 1981; Lemmon and Pearlman, 1981), the transplants offered an interesting possibility: perhaps the heterochronic neurons that had taken up residence in the upper layers would nevertheless project to their normal subcortical targets, such as the LGN (which receives no upper-layer input in normal animals).

To examine the projections of heterochronically transplanted neurons, HRP was injected into the LGN of 4 mature ferrets that had received heterochronic grafts as neonates (Table 1). The results from one animal (no. 198) are shown in Figure 28. In this experiment, HRP was injected at multiple sites in the LGN and covered a good extent of the nucleus (Fig. 28A). Retrogradely labeled neurons were found throughout most of area 17 , and also in areas 18 and SV. HRP-labeled neurons in a small region of area 17 (box in Fig. 28B) are outlined in the reconstruction shown in Figure $28 E$. As in normal ferrets, retrogradely labeled cells are found in layer 6 (primarily the lower two-thirds of the layer), and scattered cells are labeled in layer 5. In Figure $28 E$, transplanted neurons labeled with ${ }^{3} \mathrm{H}$-thymidine are shown as dots; there were 13 transplanted cells in layer $2 / 3,1$ in layer 4,1 in layer 5 , and 4 cells in layer 6 . Each of the 4 neurons in layer 6 was also retrogradely labeled with HRP. Figure $28, C$, $D$, shows a high-power view of 3 of these double-labeled neurons. A fifth double-labeled layer 6 cell was recovered from another heterochronic ferret that received an injection of HRP into the LGN, and no double-labeled cells were found in the other 2 animals. While the number of double-labeled cells is not large, these results do show that the transplanted ncurons are capable of forming long-distance axonal projections, and that at least some of these embryonically generated neurons appear committed to forming a geniculate projection, as well as to residing in layer 6 .

What of the connections of transplanted neurons in the upper layers? All that can be said from these experiments is that no upper-layer cells were retrogradely labeled with HRP from the LGN. While negative results are not compelling (particularly given the small likelihood of finding double-labeled cells to begin with), it is nevertheless worthwhile to reexamine Figure $28 E$; this shows that, despite excellent retrograde labeling of the layer 6 neurons immediately below layer $2 / 3$, no retrogradely labeled cells at all are found in the upper layers. Transplanted neurons at this retinotopic position in layer $2 / 3$ ought to have had access to HRP if they projected to the LGN; that there is no hint of retrograde labeling in this case suggests that these cells did not form a geniculate projection.

Another possibility considered was that the upper-layer transplanted neurons might project to other cortical areas, such as areas 18 and 19 , as do normal layer $2 / 3$ neurons. To test this, 2 ferrets that had received heterochronic transplants were also given injections of HRP into areas 18 and 19 (see Table 2 for details). No double-labeled cells were found in either animal: in one, the areas occupied by the ${ }^{3} \mathrm{H}$-thymidine- and HRPlabeled cells did not overlap, and in the second there was some spatial overlap but no double-labeling. While it remains very possible that the transplanted neurons in the upper layers project to areas 18 and 19 , this remains to be documented.

A final point of interest in these studies of anatomical connections concerns the transplanted cells that failed to migrate and were found in ectopic islands. Cells sitting in these islands were occasionally labeled with HRP following injection of the LGN, although only rarely ( 2 cells) were they also labeled with ${ }^{3} \mathrm{H}$-thymidine (not shown). HRP-labeled cells were multipolar in shape. These cells were found only in the ectopic clusters buried in the white matter, and not in the clusters located adjacent to the lateral ventricle. Thus, the neuronal appearance of these cells in Nissl-stained sections (Fig. 25F) and the finding that some formed axonal projections lead to the conclusion that at least some of the transplanted cells that fail to migrate in the host brain nevertheless differentiate into neurons.

\section{Discussion}

In this study, transplantation techniques were used to distinguish between 2 possible strategies that the developing nervous system might employ in generating the layers of the cerebral cortex. One possibility is that newly generated cortical neurons might be committed to their laminar fates prior to migration; an alternative is that young neurons are pluripotential and their fates are determined by environmental cues encountered during their migration into and differentiation within the cortical plate. The results suggest that both strategies may well be used: many neurons did indeed appear to be committed to their deep-layer fates prior to migration, but the laminar fates of other cells were apparently directed by environmental factors.

In normal ferrets, most neurons in area 17 that were born on or after $\mathbf{P} 1$ took up residence in layer $2 / 3$. They took about a week to reach their final positions in the cortex, migrating at a rate of roughly $10-15 \mu \mathrm{m} / \mathrm{hr}$. Many ${ }^{3} \mathrm{H}$-thymidine-labeled neurons in the upper layers of area 17 could be retrogradely labeled with HRP from areas 18 and 19 , although the overall incidence of double-labeling was small. Neurons labeled with ${ }^{3} \mathrm{H}$-thymidine on E32 are destined to sit primarily in layers 5 and 6 of the primary visual cortex. These neurons were found in their

\footnotetext{
Figure 28. Results of a heterochronic transplant in which the host was also injected with HRP into the lateral geniculate nucleus (lgn). $A$, Reconstruction of the injection site in the LGN. The tracks from 2 penetrations are shown descending through the hippocampus (hip). $B$, Reconstruction of a parasagittal view of areas 17,18 and the splenial visual area $(s v)$, in which retrogradely labeled neurons were found. Posterior is to the right. A small region of area $17(b o x)$ is reconstructed in $E$. The arrow points to the location of the 3 double-labeled neurons shown in $C$ and $D$. Scale, for $A$ and $B$. C . Three cells (arrows) labeled with ${ }^{3} \mathrm{H}$-thymidine. The plane of focus is on the silver grains overlying the cell's nuclei. $D$, The same 3 cells are also retrogradely labeled with HRP. Plane of focus on HRP reaction product in the cytoplasm. $E$, Reconstruction of the boxed region of area 17 in $B$, showing positions of HRP-labeled cells (outlined) and transplanted neurons labeled with ${ }^{3} \mathrm{H}$-thymidine (dots). Four cells in layer 6 were double-labeled, and the 3 shown in $C$ and $D$ are marked with an arrow. Retrograde labeling was confined to layers 6 and 5 ; even though many transplanted cells were in the upper layers, no HRP labeling was observed there. $w m$, White matter.
} 
final laminar positions by P1 (10 d later), and probably had reached their destination well before this time. ${ }^{3} \mathrm{H}$-thymidinelabeled neurons in layer 6 could be retrogradely labeled with HRP from the LGN, a normal target of layer 6 cells in other carnivore species (Gilbert and Kelly, 1975; McConnell and LeVay, 1986).

In isochronic transplants, ${ }^{3} \mathrm{H}$-thymidine-labeled cells from the occipital proliferative zones of newborn ferrets were labeled with a fluorescent dye, dissociated into a single-cell suspension, and transplanted back into the proliferative zone of littermate hosts. Many of these cells migrated out into the host cortical plate and differentiated into cortical neurons. When the ${ }^{3} \mathrm{H}$-thymidine marker was used to identify transplanted cells after long survivals ( $>4$ weeks), nearly all the labeled cells were found in layer $2 / 3$ of visual cortex, their normal destination. At least some of the transplanted neurons formed normal axonal projections to areas 18 and 19. It is concluded that transplantation per se does not alter the normal fate of cortical neurons.

In heterochronic transplants, cells from E31 or E32 donors were challenged to alter their normal fates after injection into the proliferative zone of a $\mathrm{P} 2$ ferret host. As in isochronic transplants, some dye-labeled cells migrated out radially to the cortical plate and developed pyramidal neuronal morphologies; a sccond group was found in all regions of the cerebral mantle and exhibited morphologies typical of astrocytic glial cells. The ${ }^{3} \mathrm{H}$-thymidine label served as a permanent marker for both a cell's donor origin and its birthday (and thus its normal laminar fate). Overall, about $80 \%$ of the ${ }^{3} \mathrm{H}$-thymidine-labeled cells in heterochronic transplants failed to migrate to the cortex and were found in ectopic clusters buried deep in the white matter or near the lateral ventricle. The remaining radioactively labeled cells migrated into the visual cortex and were distributed unequally among the cortical layers: about $43 \%$ were in layer $2 / 3$, and the remaining $57 \%$ were distributed throughout the deeper layers but primarily in layers 5 and 6 . Several heterochronically transplanted neurons in layer 6 were retrogradely labeled with HRP from the LGN, a target appropriate for their donor origin. Thus, while many of the transplanted neurons appeared to follow environmental directives and migrated to the upper layers, a substantial fraction was found in their normal laminar positions, and at least some of these formed axonal projections typical of their birthday. The conclusion follows that a subpopulation of neurons generated on E31/32 appears to be committed to a deep-layer fate prior to migration.

\section{Commitment in cerebral cortex}

Several previous lines of evidence have suggested that neurons in the cerebral cortex may be committed to their laminar fates early on in development. In the reeler mouse, for example, although neurons are generated along a normal timetable (Caviness and Sidman, 1973), their migration is apparently blocked in the cortical plate so that younger neurons fail to migrate past older neurons (Pinto Lord et al., 1982). Thus, the cortical layers in reeler are roughly inverted compared to normal; nevertheless, reeler neurons apparently establish the normal arrays of anatomical connections and functional properties typical of their cell class (Caviness, 1976; Dräger, 1981; Lemmon and Pearlman, 1981). In another system, Jensen and Killackey (1984) deliberately altered the migration patterns of young neurons by irradiating rat fetuses. They found that many neurons were located in ectopic positions-some were in the wrong cortical lamina, and others had failed to migrate altogether-yet, in spite of these abnormal positions, many cells formed apparently normal spinal projections. These results have led several authors to suggest that the commitment of cortical neurons must occur early in their development, probably prior to migration (Caviness, 1982; Jensen and Killackey, 1984; Rakic, 1985). The present results add support to this view, at least for a population of presumptive deep-layer neurons.

A distinction must be made, however, between the commitment of a cortical neuron to a general laminar fate and its decision to innervate a particular specified target. The latter can clearly be influenced by positional information (Stanfield and O'Leary, 1985b). Early in their development, layer 5 neurons throughout the cerebral cortex of rodents extend an axon into the pyramidal tract; however, cells in the occipital cortex eliminate this early, "exuberant" axon and form stable connections to the tectum (Stanfield et al., 1982; Stanfield and O'Leary, 1985a; O'Leary and Stanfield, 1985, 1986). If a piece of occipital cortex is transplanted forward into the rostral cortex (where layer 5 neurons maintain their projections to the spinal cord), the normally transient pyramidal tract axons from the occipital neurons are rescued from elimination (Stanfield and O'Leary, 1985b). Thus, information related to a neuron's position in the cerebral cortex can apparently direct a cell's choice among several potential targets. Similarly, Chang et al. (1986) have shown that the position of a transplanted piece of cortex, and not its origin, appears to determine the pattern of callosal inputs to the cortex.

Neither of these results implies that there are no intrinsic differences between cortical neurons in different layers. Quite to the contrary, studies of normal development show that laminar differences appear quite early. For example, only layer 5 neurons ever send axons into the pyramidal tract (Stanfield et al., 1982) or to the superior colliculus (Thong and Dreher, 1986), and not cells from other layers. Furthermore, the observation that migrating cerebral cortical neurons destined for the upper layers in the monkey can extend an axon to the contralateral hemisphere (Schwartz and Goldman-Rakic, 1986) suggests that neurons begin to form connections before their final position is even reached.

In the present experiments, a subpopulation of presumptive deep-layer neurons did indeed recognize their intrinsically specified laminar position, and some formed axonal connections appropriate for normal layer 6 cells in the primary visual cortex. One synthesis of these and previous experimental results is to suggest that at least some cortical neurons are committed to a laminar fate, given by their birthday, that determines their laminar position in the cortex and specifies the range of connections that may form. For layer 5 cells, for example, although intrinsic cues may direct them to project subcortically, positional information is also used to select the most appropriate targets from a limited range of possibilities. This type of developmental program would appear to provide a most expedient combination of specificity in development with plasticity of choice: the intrinsic specification of general patterns of connections would provide a framework on which particular, regional needs could be built. How these developmental choices are made-the exact nature of the intrinsic and environmental cues that direct development-remains a mystery.

\section{Relationship between laminar position and connections}

The question of whether laminar position and the pattern of connections can ever be dissociated cleanly from each other bears further discussion. This relates particularly to the problem 
of the heterochronically transplanted neurons that sit in the upper layers rather than in the deep layers. Do these cells elaborate typical deep-layer projections in spite of their laminar position, or are both their positions and connections characteristic of layer $2 / 3$ ? The projections of these neurons could not be identified in the present experiments, but it appears unlikely that they project to the LGN. Even if the upper-layer heterochronic ncurons had becn shown to make cortical connections to areas 18 and 19 , this result would be difficult to interpret. Although it would be tempting to conclude that this group represented a pluripotential group of cells that altered their normal fates upon transplantation, such a conclusion would be cavalier, since there is a small population of deep-layer neurons that projects to areas 18 and 19 in the normal ferret. The possibility would remain that the heterochronic cells sorted out into layers on the basis of their intrinsically specified projections. There are other possible bases for the heterochronic neurons' failure to behave as a unified population. One is that some E32 neurons normally take up residence in the superficial layers. Another is that the transplanted cells may have sorted out into groups of projection neurons (deep layers) and interneurons (superficial). A third possibility is that the upper-layer neurons represent a population of cells that would have died during normal development, or, alternatively, cells that would have continued to divide during normal development and dilute out their ${ }^{3} \mathrm{H}$ thymidine label. And a final possibility is that normally both intrinsic and environmental cues are used together in laminar development and, under normal conditions, the 2 act in concert; when the 2 sets of signals provide contradictory information, neurons may sort out in a probabilistic manner between the 2 alternate sets of fates.

Many of the problems encountered in interpreting the heterochronic transplant results hinge on 2 issues: one is the validity of the assumption that the ${ }^{3} \mathrm{H}$-thymidine label is a marker of a cell's normal fate, and the second is a problem with any population transplantation study: that there might be a differential survival or selection of cells under different conditions. These 2 issues are related in the sense that ${ }^{3} \mathrm{H}$-thymidine is at least theoretically incorporated into 3 cell types during normal development: cells that will normally end up in layer $5 / 6$, cells that will normally die, and stem cells that normally continue dividing and produce cells other than layer $5 / 6$ neurons. That the second and third types might be abnormally represented after heterochronic transplantation and confused with cells of the first type is a potential problem in these experiments.

A final issue that remains unresolved is whether laminar position and projection pattern are specified independently in the deep-layer heterochronic neurons. Since the entire population of cells with connections to the LGN was in layer 6, it seems possible that only the cell's laminar position was previously specified; once in layer 6 , the cell was instructed by local cues to extend a geniculate axon. This seems unlikely given the results in reeler cortex (Caviness, 1982) and in the irradiation experiments of Jensen and Killackey (1984), in which neurons formed normal connections even though they did not sit in their normal laminar positions. However, this possibility cannot be ruled out in the present transplants.

\section{Morphology as a function of laminar position}

Not only do the connections of normal neurons vary as a function of their laminar position, but their morphologies differ from layer to layer as well. From looking at ${ }^{3} \mathrm{H}$-thymidine-labeled neurons in Nissl-stained sections of heterochronic host brains, however, the most one can conclude from their morphologies is that the transplanted neurons appeared similar to other cells within the layer. This material yielded little of the information about dendritic morphology and local axonal projections that can be gleaned from Golgi impregnation or intracellular fills.

It is not clear to what extent one would expect neuronal morphology to be intrinsically determined. In reeler cortex, for example, there is an unusually large number of upside-down pyramidal neurons (Caviness and Rakic, 1978). One hypothesis is that dendritic morphologies are determined through interactions between growing dendrites and axon-rich zones: in both reeler and normal mice, dendrites seem to grow into these zones, so that cells lying within axon-rich strata become multipolar in configuration, whereas cells lying outside elaborate dendrites into the zone from their nearest polar process (Pinto Lord and Caviness, 1979). A similar correlation between thalamic afferents and the branching of pyramidal cell dendrites has been observed in monkey somatosensory cortex (Hendry and Jones, 1983).

The most direct way to examine the detailed morphology of transplanted neurons would be to inject them with an intracellular tracer. One conceivable way of performing this experiment would be to introduce a long-lasting fluorescent marker into the cells prior to transplantation, and then use this marker to target neurons for intracellular injection in tissue slices (Katz et al., 1984). Besides the cell's dendritic morphology, one might be able to study the local axon collaterals of the neuron as well. The pattern of intrinsic connections formed by a normal neuron is characteristic of its laminar position (Gilbert and Wiesel, 1979; Martin and Whitteridge, 1984). Studying the long-distance projections of transplanted neurons is made very difficult by the small numbers of transplanted cells and their unpredictable distribution; characterization of their local projections would thus be a welcome addition to the connectivity studies discussed above.

\section{Implications for mechanisms of migration}

Young cortical neurons are thought to use radial glial cells as guidewires for their migration out to the cortical plate (Rakic, $1972,1978,1985)$. Once in the cortical plate, however, it has been unclear how neurons are signaled to detach from the radial glia and differentiate. One possibility has been that the radial glia simply function as a kind of conveyor belt-perhaps all migrating neurons simply get dumped off at the top of the cortical plate. The laminar grouping of cells by birthday could be thought of as an epiphenomenon of this process, resulting from each cohort of neurons beginning migration at roughly the same time. An alternative is that laminar formation is a more active process that involves a cell's recognition of its birth cohort of neurons and selective affinity to those cells.

The heterochronic transplantation results suggest the latter. Over half of the labeled cells that migrated out to the cortex apparently terminated their migration early and were found deep to layer $2 / 3$ (where nearly all isochronic neurons ended up). E32 ${ }^{3} \mathrm{H}$-thymidine injections in normal animals showed that neurons in layers 5 and 6 are in their final positions by the time of birth in the ferret. Thus, cells in these layers may have been recognized by the migrating, heterochronically transplanted neurons as belonging to the same birth cohort. It is not known whether, for example, there might be lamina-specific cell-surface markers that signal laminar identity, or by what mechanism a 
neuron's migration is terminated. Nor is it known why, if there are such markers, not all of the ${ }^{3} \mathrm{H}$-thymidine-labeled cells responded to them.

\section{Rates of migration of normal and transplanted neurons}

Normal neurons generated on $\mathrm{Pl}$ migrated out to the cortical plate at a rate of about $10-15 \mu \mathrm{m} / \mathrm{hr}$, an estimate that is intermediate between the rates calculated for the rat $(15-30 \mu \mathrm{m} / \mathrm{hr}$; Hicks and D'Amato, 1968) and monkey (0.5-10 $\mu \mathrm{m} / \mathrm{hr}$; Rakic, 1985). As has been pointed out previously by Hicks and D'Amato (1968), such figures are at best only rough estimates of the actual migration rate and contain large margins for error. There are many difficulties in determining the length of the actual path traversed by a migrating neuron: the neuron's target destination in the cortical plate recedes from the cell with the growth of the plate; the cell's migratory pathway becomes increasingly tortuous as the cortex convolutes to form its sulci and gyri; and the intermediate zone through which a migrating cell has already traveled continues to expand with the invasion of ingrowing and outgoing axons. Other uncertainties inherent in these estimates have been mentioned by Rakic (1978), and include variabilities in the length of the cell-generation cycle and the time that it takes for a ${ }^{3} \mathrm{H}$-thymidine-labeled neuron to initiate migration, and the possibility that movement during migration may be interspersed with rests or stops of unknown duration. In spite of these problems and uncertainties, the migration rates calculated here are probably a good estimate of at least the magnitude of the actual migration rate. In fact, they bear a surprising similarity to the migration rates of cerebellar granule neurons along astrocytic processes in vitro $(10 \mu \mathrm{m} / \mathrm{hr}$; Hatten et al., 1984), in which migration was observed directly by time-lapse video microscopy.

Estimates of the rate of migration of transplanted neurons are even more difficult than in the normal case, given the variability in the starting points of neurons within injection sites (which, as shown in Figs. $13 A$ and $14 A$, usually extend into the intermediate zone), and the fact that cells were transplanted several hours after the final ${ }^{3} \mathrm{H}$-thymidine injection, which would allow time for many or all cells to complete their mitotic cycle prior to transplantation. It would appear, nevertheless, that the transplanted neurons migrated at a rate roughly comparable to that of normal cells, since they arrived at the top of the cortical plate about 4-6 d after transplantation, as compared to about a week for normal neurons. Presumably, the slight lead of the transplanted cells was due to the head start granted to them by both their initial position in the host brain and their advanced stage in the cell cycle.

\section{Transplanted cells with glial morphologies}

In both types of transplants, a substantial population of dyelabeled, transplanted cells - in fact, the great majority - was neither labeled with ${ }^{3} \mathrm{H}$-thymidine nor had developed morphologies typical of cortical neurons. These cells were eventually found in all layers of the cerebral mantle and differentiated into round cells with fine processes that radiated irregularly outward from the cell body. Although this group of cells resembled young astrocytes, only one of the dye-labeled cells in these transplants showed GFA immunoreactivity. It seems possible that the fluorescent dyes used to label the transplanted cells might interfere with the antibodies' access to GFA and thus obscure their identity. However, because this population of cells was not labeled with ${ }^{3} \mathrm{H}$-thymidine, it was impossible to screen them for GFA immunoreactivity in the absence of the dye label. The other possibility is that these cells simply do not express GFA. (It is conceivable but unlikely that these dye-labeled cells were oligodendrocytes; this class of glial cell does not begin to mature until neuronal migration has ceased; Jacobson, 1978).

Given their morphology and the fact that the dye-labeled cells were not labeled with ${ }^{3} \mathrm{H}$-thymidine, it seems most likely that thesc were astroglial cclls. In gencral, it is certainly not surprising that the proliferative zone should contain more than those cells destined to become cortical neurons. This zone is believed to produce glia as well as neurons, and, in many animals, ventricular zone cells are heterogeneous with respect to glia- and neuron-specific markers, suggesting the presence of both glia- and neuron-producing stem cells (Levitt et al., 1981; Bennett and DiLullo, 1985a, b). Furthermore, evidence in the monkey suggests that the proportion of GFA-positive mitotic profiles in the ventricular zone (presumed glial cell precursors) increases with time, so that by the time neurons in the upper layers are being generated, glial precursors form a substantial majority of proliferating cells (Levitt et al., 1983). Thus, it seems particularly likely in the isochronic transplants that a similarly large proportion of dye-labeled, transplanted cells are young glial cells.

The mechanism by which these cells move from the injection site into the other regions of the cerebral mantle after transplantation is unclear, and, without separate markers for young neurons and glia, will probably remain so. However, it does seem that the cells moved rapidly-nearly as rapidly as the spindle-shaped migrating neurons, which appeared (frozen in time, as they were) to be leading the charge out to the cortical plate. The morphology of the glial cells during their migration is unclear, since this class of cell is defined by its differentiated morphology. Nevertheless, at short times after transplantation, while the bulk of cell movement was occurring, there was an abundance of dye-labeled cells with round nuclei and simple, seemingly undifferentiated morphologies (one might see a few short, blunt processes extending out a small distance), raising speculation that the glial cells might be amoeboid in their movement. Unfortunately, these experiments have produced more questions than answers about the nature and development of this population of cells.

\section{Ectopic clusters of transplanted cells}

In the heterochronic transplants, many transplanted cells were found in ectopic clusters buried deep in the white matter or near the lateral ventricle. Because of their position, it is believed that thesc cells failed to migrate and instead remained at the site of the original injection. The fact that many of these cells were labeled with ${ }^{3} \mathrm{H}$-thymidine suggests two possibilities for their identity. The first is that these were bona fide presumptive layer $5 / 6$ neurons that somehow didn't know how to migrate in an older brain. The second is that these were stem cells whose normal pattern of mitotic divisions was arrested by the dissociation or transplantation procedures.

Both interpretations have some merit. It has been suggested, for example, that the mechanism of migration employed very early in development, when the cerebral vesicle is very small, may be independent of radial glial fibers and may instead depend on continued cell-cell contacts (Meller and Tetzlaff, 1975; Shoukimas and Hinds, 1978). Thus, some of the embryonically generated neurons may have been unable to recognize and migrate along the radial glial guides present at a later age (although, 
clearly, many of the heterochronically transplanted neurons were able to migrate).

The impression gained from the layout and morphology of transplanted cells in the ectopic clusters was that both possibilities - that both presumptive layer $5 / 6$ neurons and arrested stem cells were represented-may be true. One hypothesis is that, while many of the transplanted cells rapidly dispersed into the host cerebral mantle, others reaggregated and formed small islands of transplanted cells, as has been shown in other studies of transplanted cell suspensions (Doering and Federoff, 1982; Floeter and Jones, 1984). It is even possible that the transplanted cells reformed small ventricular zones, since cells that were most heavily labeled with ${ }^{3} \mathrm{H}$-thymidine tended to be found at the outer edges of the cluster, with more lightly or unlabeled cells within. Many cells in these clusters had morphologies that looked neuronal, and some even formed axonal connections to the LGN.

It might be asked why cells taken from embryonic, but not postnatal, donors should exhibit this behavior (since no ectopic clusters were found in isochronic transplants). One likely explanation is that the proliferative zone probably consists of a variety of cell types-neuronal stem cells and glial stem cells among them-and that the proportions of these types change over time, the glial precursors becoming increasingly prevalent later in development (Levitt et al., 1983). If neuron-producing stem cells are both more numerous around E32 and less capable than glial precursors of developing normally after dissociation, they may be much more prone to the abnormal patterns of development observed after transplantation than are the postnatal donor cells.

\section{Use of transplants in exploring normal development}

The use of transplants to investigate normal developmental processes obviously has very different goals than that which centers on testing the ability of transplanted nervous tissue to functionally reinnervate damaged areas of the adult brain (reviewed in Gash et al., 1985). The degree of incorporation of transplanted cells into host brains in the present experiments is in marked contrast to the results of most transplantation studies, in which transplanted neurons (even when transplanted as a suspension) show a strong tendency to aggregate with one another, rather than to disperse into the host brain. While the age of the donor tissue clearly influences the extent to which cell aggregation occurs following transplantation (discussed above), the main source of the difference between these transplants and others may be due in large part to the age of the host animal. In the present transplants, the host brain presents an cnvironment in which the important developmental processes-migration, differentiation, axogenesis - are ongoing. It would be surprising to find that proliferative zone cells transplanted to an adult brain are capable of migration in the absence of the environmental machinery (such as radial glial cells) that supports this process. It would be interesting to examine the time period over which the ferret's brain is capable of supporting the migration of transplanted cells, or indeed, whether the continued presence of neurons capable of migration would prolong this period.

Another issue not addressed in the present experiments is that of positional cues that might influence developmental choices. All of the isochronic transplants discussed here were homotopic, i.e., presumptive visual cortical neurons were transplanted back into the occipital cerebral mantle. Neurons normally destined to sit in other cortical areas (or other regions of the brain or spinal cord) have not been subjected to heterotopic transplantation using these methods. However, recent studies involving transplantation of small pieces of cortical tissue have suggested that both the efferent projections from and afferent input to a cortical transplant show some dependence on the position of the tissue in the host brain rather than on its site of origin (Stanfield and O'Leary, 1985b; Chang et al., 1986). It would be interesting to use heterotopic transplantation techniques to bcgin to test the limits that are placed by a neuron's intrinsic makeup on the range of developmental outcomes it may achieve.

\section{References}

Angevine, J. B., Jr., and R. L. Sidman (1961) Autoradiographic study of cell migration during histogenesis of cerebral cortex in the mouse. Nature 192: 766-768.

Bennett, G. S., and C. DiLullo (1985a) Expression of a neurofilament protein by the precursors of a subpopulation of ventral spinal cord neurons. Dev. Biol. 107: 94-106.

Bennett, G. S., and C. DiLullo (1985b) Transient expression of a neurofilament protein by replicating neuroepithelial cells of the embryonic chick brain. Dev. Biol. 107: 107-127.

Bignami, A., L. F. Eng, D. Dahl, and C. T. Uyeda (1972) Localization of the glial fibrillary acidic protein in astrocytes by immunofluorescence. Brain Res. 43: 429-435.

Caviness, V. S., Jr. (1976) Patterns of cell and fiber distribution in the neocortex of the reeler mutant mouse. J. Comp. Neurol. 170:435448

Caviness, V. S., Jr. (1982) Neocortical histogenesis in normal and reeler mice: A developmental study based on $\left[{ }^{3} \mathrm{H}\right]$ thymidine autoradiography. Dev. Brain Res. 4: 293-302.

Caviness, V. S., Jr., and P. Rakic (1978) Mechanisms of cortical development: A view from mutations in mice. Annu. Rev. Neurosci. 1: 297-326.

Caviness, V. S., Jr., and R. L. Sidman (1973) Time of origin of corresponding cell classes in the cerebral cortex of normal and reeler mutant mice: An autoradiographic analysis. J. Comp. Neurol. 148: 141-151.

Chang, F.-L. F., J. G. Steedman, and R. D. Lund (1986) The lamination and connectivity of embryonic cerebral cortex transplanted into newborn rat cortex. J. Comp. Neurol. 244: 401-411.

Doering, L. C., and S. Federoff (1982) Isolation and identification of neuroblast precursor cells from mouse neopallium. Dev. Brain Res. 5: 229-233.

Dräger, U. C. (1981) Observations on the organization of the visual cortex in the reeler mouse. J. Comp. Neurol. 201: 555-570.

Floeter, M. K., and E. J. Jones (1984) Connections made by transplants to the cerebral cortex of rat brains damaged in utero. J. Neurosci. 4: 141-150.

Frank, E., W. A. Harris, and M. B. Kennedy (1980) Lysophosphatidylcholine facilitates labeling of CNS projections with horseradish peroxidase. J. Neurosci. Methods 2: 183-185.

Gash, D. M., T. J. Collier, and J. R. Sladek, Jr. (1985) Neural transplantation: A review of recent developments and potential applications to the aged brain. Neurobiol. Aging 6: 131-150.

Gilbert, C. D. (1977) Laminar differences in receptive field properties of cells in cat primary visual cortex. J. Physiol. (Lond.) 268: 391421.

Gilbert, C. D. (1983) Microcircuitry of the visual cortex. Annu. Rev. Neurosci. 6: 217-247.

Gilbert, C. D., and J. P. Kelly (1975) The projections of cells in different layers of the cat's visual cortex. J. Comp. Neurol. 163: 81106.

Gilbert, C. D., and T. N. Wiesel (1979) Morphology and intracortical projections of functionally characterised neurons in the cat visual cortex. Nature 280: 120-125.

Hatten, M. E., R. K. H. Liem, and C. A. Mason (1984) Two forms of cerebellar glial cells interact differently with neurons in vitro. J. Cell Biol. 98: 193-204.

Hendry, S., and E. G. Jones (1983) The organization of pyramidal and nonpyramidal cell dendrites in relation to thalamic afferent terminations in the monkey somatic sensory cortex. J. Neurocytol. 12: 277-298. 
Hicks, S. P., and C. J. D'Amato (1968) Cell migrations to the isocortex in the rat. Anat. Rec. 160: 619-634.

Huettner, J. E., and R. W. Baughman (1986) Primary culture of identified neurons from the visual cortex of postnatal rats. J. Neurosci. 6: 3044-3060.

Jackson, C. A., J. D. Peduzzi, and T. L. Hickey (1984) Genesis of visual cortical neurons in the ferret. Soc. Neurosci. Abstr. 10:519.

Jacobson, M. (1978) Developmental Neurobiology, Plenum, New York.

Jensen, K. F., and H. P. Killackey (1984) Subcortical projections from ectopic neocortical neurons. Proc. Natl. Acad. Sci. USA 81: 964-968.

Katz, L. C., A. Burkhalter, and W. J. Dreyer (1984) Fluorescent latex microspheres as a retrograde neuronal marker for in vivo and in vitro studies of visual cortex. Nature 310: 498-500.

Kostovic, I., and P. Rakic (1980) Cytology and time of origin of interstitial neurons in the white matter in infant and adult human and monkey telencephalon. J. Neurocytol. 9: 219-242.

Lemmon, V., and A. L. Pearlman (1981) Does laminar position determine the receptive field properties of cortical neurons? A study of corticotectal cells in area 17 of the normal mouse and the reeler mutant. J. Neurosci. 1: 83-93.

LeVay, S., and H. Sherk (1981) The visual claustrum of the cat. I. Structure and connections. J. Neurosci. 1: 956-980.

LeVay, S., S. K. McConnell, and M. B. Luskin (1987) Functional organization of primary visual cortex in the mink (Mustela vison), and a comparison with the cat. J. Comp. Neurol. 257: 422-441.

Levitt, P., M. L. Cooper, and P. Rakic (1981) Coexistence of ncuronal and glial precursor cells in the cerebral ventricular zone of the fetal monkey: An ultrastructural immunoperoxidase analysis. J. Neurosci. I: $27-39$.

Levitt, P., M. L. Cooper, and P. Rakic (1983) Early divergence and changing proportions of neuronal and glial precursor cells in the primate cerebral ventricular zone. Dev. Biol. 96: 472-484.

Linden, D. C., R. W. Guillery, and J. Cucchiaro (1981) The dorsal lateral geniculate nucleus of the normal ferret and its postnatal development. J. Comp. Neurol. 203: 189-211.

Luskin, M. B., and C. J. Shatz (1985a) Neurogenesis of the cat's primary visual cortex. J. Comp. Neurol. 242: 611-631.

Luskin, M. B., and C. J. Shatz (1985b) Studies of the earliest generated cells of the cat's visual cortex: Cogeneration of subplate and marginal zones. J. Neurosci. 5: 1062-1075.

Martin, K. A. C., and D. Whitteridge (1984) Form, function and intracortical projections of spiny neurones in the striate visual cortex of the cat. J. Physiol. (Lond.) 353: 463-504.

McConnell, S. K. (1985a) Migration and fate of transplanted visual cortical neurons. Soc. Neurosci. Abstr. 11: 806.

McConnell, S. K. (1985b) Migration and differentiation of cerebral cortical neurons after transplantation into the brains of ferrets. Science 229: 1268-1271.

McConnell, S. K. (1986) Fate of visual cortical neurons after heterochronic transplantation. Soc. Neurosci. Abstr. 12: 1371.

McConnell, S. K., and S. LeVay (1984) Segregation of on- and offcenter afferents in mink visual cortex. Proc. Natl. Acad. Sci. USA 81 : $1590-1593$

McConnell, S. K., and S. LeVay (1986) Anatomical organization of the visual system of the mink (Mustela vison). J. Comp. Neurol. 250. 109-132.

McCourt, M. E., J. Boyapati, and G. H. Henry (1986) Layering in lamina 6 of cat striate cortex. Brain Res. 364: 181-185.

Meller, K., and W. Tetzlaff (1975) Neuronal migration during the early development of the cerebral cortex. A scanning electron microscope study. Cell Tissue Res. 163: 313-325.

Mesulam, M.-M. (1978) Tetramethyl benzidine for horseradish peroxidase neurohistochemistry: A non-carcinogenic blue reaction-product with superior sensitivity for visualizing neural afferents and efferents. J. Histochem. Cytochem. 26: 106-117.

Meyer, G., and K. Albus (1981) Spiny stellates as cells of origin of association fibers from area 17 to area 18 in the cat's neocortex. Brain Res. 210: 335-341.

Moody, K. D., T. A. Bowman, and C. M. Lang (1985) Laboratory management of the ferret for biomedical research. Lab Anim. Sci. 35: 272-279.

O'Leary, D. D. M., and B. B. Stanfield (1985) Occipital cortical neurons with transient pyramidal axons extend and maintain collaterals to subcortical but not intracortical targets. Brain Res. 336: 326-333.

O'Leary, D. D. M., and B. B. Stanfield (1986) A transient pyramidal tract projection from the visual cortex in the hamster and its removal by selective collateral elimination. Dev. Brain Res. 27: 87-99.

Olucha, F., F. Martinez-Garcia, and C. Lopez-Garcia (1985) A new stabilizing agent for the tetramethylbenzidine (TMB) reaction product in the histochemical detection of horseradish peroxidase (HRP). J. Neurosci. Mcthods 13: 131-138.

Pinto Lord, M. C., and V. S. Caviness, Jr. (1979) Determinants of cell shape and orientation: A comparative Golgi analysis of cell-axon interrelationships in the developing neocortex of normal and reeler mice. J. Comp. Neurol. 187: 49-70.

Pinto Lord, M. C., P. Evrard, and V.S. Caviness, Jr. (1982) Obstructed neuronal migration along radial glial fibers in the neocortex of the reeler mouse: A Golgi-EM analysis. Dev. Brain Res. 4: 379-393.

Rakic, P. (1972) Mode of cell migration to the superficial layers of fetal monkey neocortex. J. Comp. Neurol. 145: 61-84.

Rakic, P. (1974) Neurons in the rhesus monkey visual cortex: Systematic relation between time of origin and eventual disposition. Science 183: 425-427.

Rakic, P. (1978) Neuronal migration and contact guidance in the primate telencephalon. Postgrad. Med. J. 54: 25-40.

Rakic, P. (1985) Contact regulation of neuronal migration. In The Cell in Contact: Adhesions and Junctions as Morphogenetic Determinants, G. M. Edelman and J.-P. Thiery, eds., pp. 67-91, Neurosciences Research Foundation, Cambridge.

Rockland, K. S (1985) Anatomical organization of primary visual cortex (area 17) in the ferret. J. Comp. Neurol. 241: 225-236.

Rye, D. B., C. B. Saper, and B. H. Wainer (1984) Stabilization of the tetramethylbenzidine (TMB) reaction product: Application for retrograde and anterograde tracing, and combination with immunohistochemistry. J. Histochem. Cytochem. 32: 1145-1153.

Schmechel, D. E., and P. Rakic (1979) A Golgi study of radial glial cells in developing monkey tenlecephalon: Morphogenesis and transformation into astrocytes. Anat. Embryol. (Berl.) 156: 115-152.

Schwartz, M. L., and P. S. Goldman-Rakic (1986) Some callosal neurons of the fetal monkey frontal cortex have axons in the contralateral hemisphere prior to the completion of migration. Soc. Neurosci. Abstr. 12: 1211 .

Shimada, M., and J. Langman (1970) Cell proliferation, migration and differentiation in the cerebral cortex of the golden hamster. J. Comp. Neurol. 139: 227-244.

Shoukimas, G. M., and J. W. Hinds (1978) The development of the cerebral cortex in the embryonic mouse: An electron microscopic serial section analysis. J. Comp. Neurol. 179: 795-830.

Stanfield, B. B., and D. D. M. O'Leary (1985a) The transient corticospinal projection from the occipital cortex during the postnatal development of the rat. J. Comp. Neurol. 238: 236-248.

Stanfield, B. B., and D. D. M. O'Leary (1985b) Fetal occipital cortical neurones transplanted to the rostral cortex can extend and maintain a pyramidal tract axon. Nature 313: 135-137.

Stanfield, B. B., D. D. M. O'Leary, and C. Fricks (1982) Selective collateral elimination in early postnatal development restricts cortical distribution of rat pyramidal tract neurons. Nature 298: 371-373.

Stent, G. S. (1985) The role of cell lineage in development. Phil. Trans. R. Soc. Lond. [Biol.] 312: 3-19.

Symonds, L. L., and A. C. Rosenquist (1984) Laminar origins of visual corticocortical connections in the cat. J. Comp. Neurol. 229: 39-47.

Thong, I. G., and B. Dreher (1986) The development of the corticotectal pathway in the albino rat. Dev. Brain Res. 25: 227-238.

Vaughan, D. W. (1984) The structure of neuroglial cells. In Cerebral Cortex, vol. 2, E. G. Jones and A. Peters, eds., Plenum, New York.

Zahs, K. R., and M. P. Stryker (1986) Physiological evidence for on and off patches within layer IV of ferret visual cortex. Soc. Neurosci. Abstr. 12: 583 . 